\title{
Thermal Properties and Thermal Modeling of Ballistic Clay Box
}
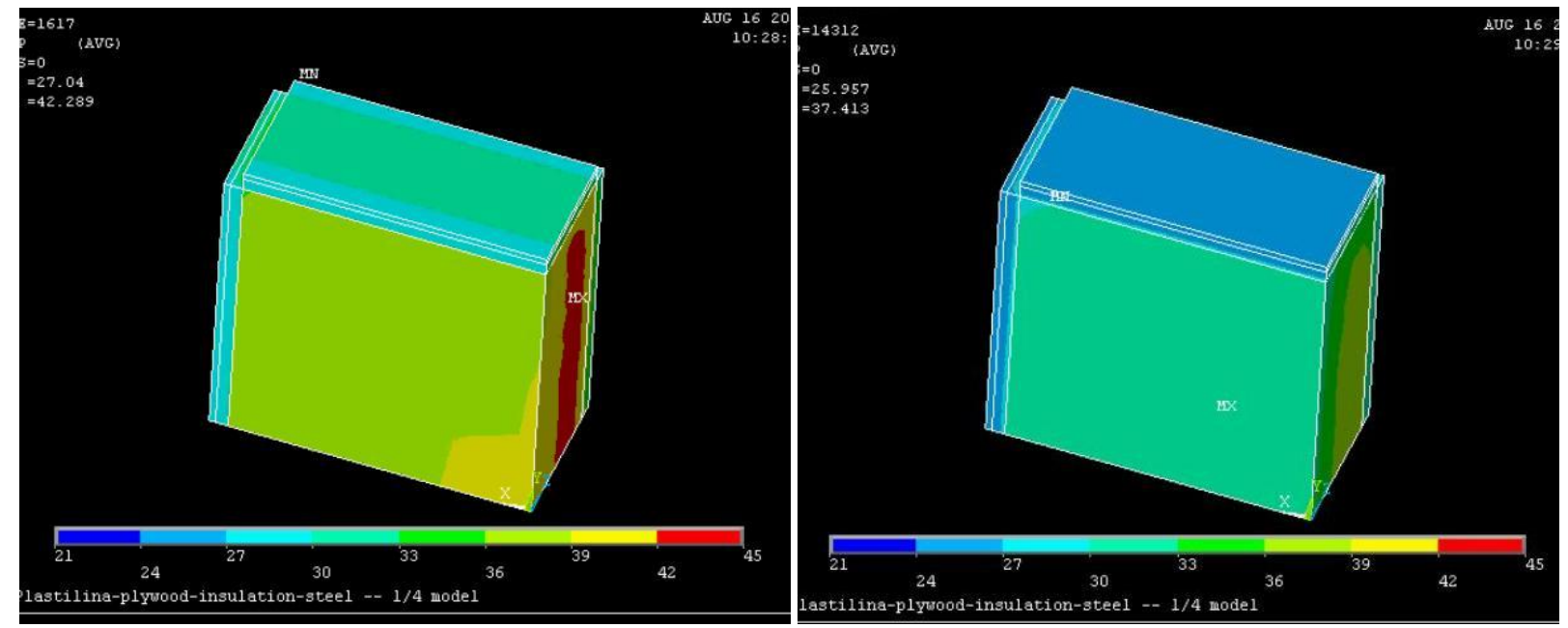

Dale P. Bentz

Amanda Forster

Kirk Rice

Michael Riley 



\title{
Thermal Properties and Thermal Modeling of Ballistic Clay Box
}

\author{
Dale P. Bentz \\ Materials and Structural Systems Division \\ Engineering Laboratory \\ Amanda Forster \\ Kirk Rice \\ Michael Riley \\ Law Enforcement Standards Office
}

National Institute of Standards and Technology

Gaithersburg, MD 20899

December 2011

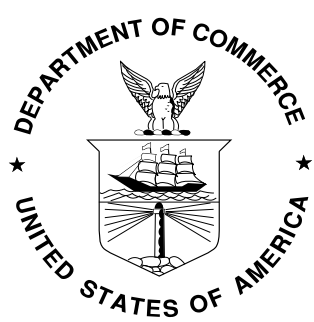

U.S. Department of Commerce John Bryson, Secretary

National Institute of Standards and Technology

Patrick D. Gallagher, Director 



\begin{abstract}
A critical component of hard and soft body armor testing is the utilization of a clay block behind the target being evaluated. One of the performance metrics used to evaluate products is the penetration depth into the clay of an indentation produced by a ballistic event. As the formulation and properties of the clay commonly employed in this application have changed over the years, it has become necessary to pre-condition the clay block test assemblage in an oven nominally set at $43{ }^{\circ} \mathrm{C}$. Upon removal from the oven, the clay block begins to cool, potentially changing its ballistic performance. To better understand the potential influence of this cooling on testing results, experimental studies have been conducted to determine a variety of thermophysical properties of the ballistic clay (Plastilina \#1) and plywood used in constructing the clay block test frames employed in ballistic testing. Properties assessed included density, thermal conductivity, heat capacity, and emissivity. These measured properties have been subsequently employed in three-dimensional computer models to predict the heating and cooling response of the test setup when placed in or removed from the oven, respectively. The simulation temperatures achieved at various locations within the clay in the test setup have been compared to experimentally measured values at the same locations for several different heating, cooling, and cooling/reheating scenarios of interest. In general, the agreement between experimental and model results is reasonable, verifying that three-dimensional simulations can be employed to predict the thermal response of the test setup. The models have been further applied to investigate the influence of the metal (steel or aluminum) used as the exterior frame of the test setup and also to evaluate the potential performance benefits of incorporating a layer of polystyrene insulation between the clay and metal frame.
\end{abstract}




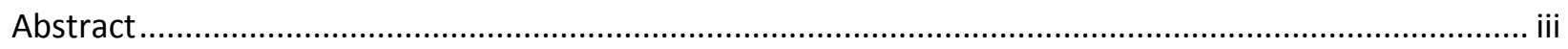

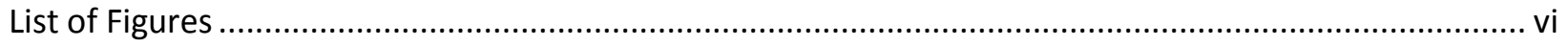

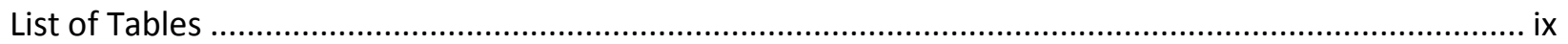

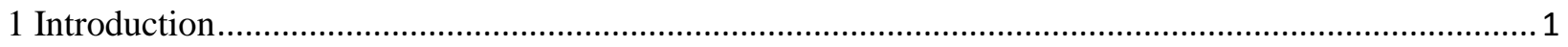

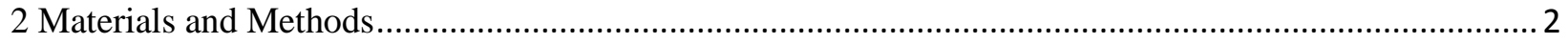

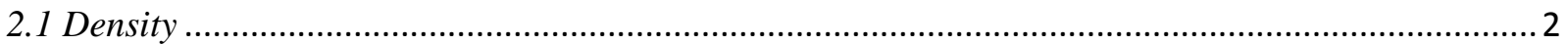

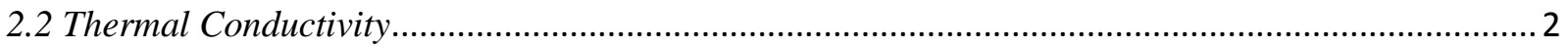

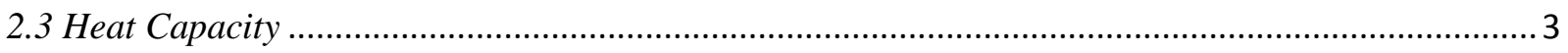

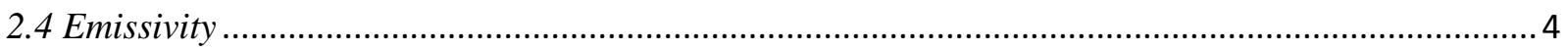

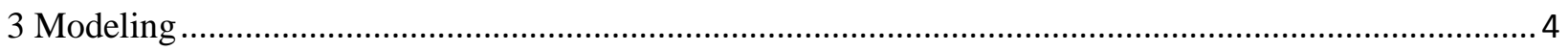

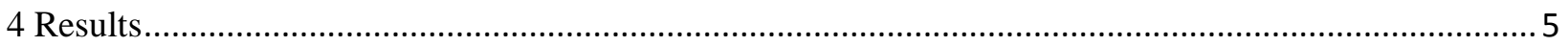

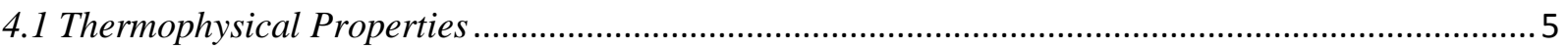

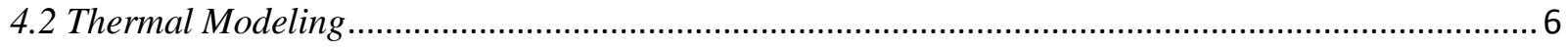

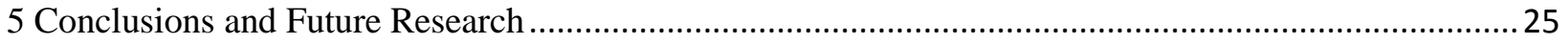

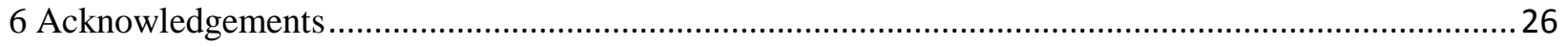

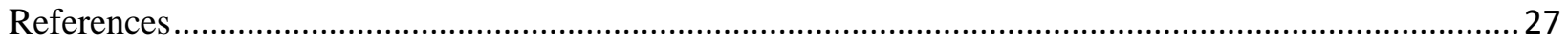

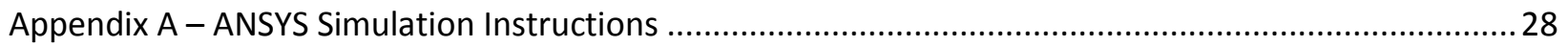




\section{List of Figures}

Figure 1. Basic configuration for measuring thermal properties using the Hot Disk Thermal Constants

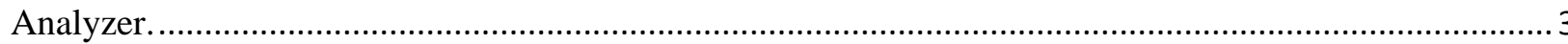

Figure 2. Predictions for system temperature via lumped heat capacity analysis with a variable natural convection heat transfer coefficient, $h$.

Figure 3. Comparison of lumped heat capacity analysis predictions for the clay/plywood/steel frame test setup for the cases of constant and variable natural convection heat transfer coefficients.

Figure 4. Comparison of lumped heat capacity, Heisler, and ANSYS analyses for the case of only the clay block cooling after removal from the oven.

Figure 5. 3-D representation of metal frame around the clay block, showing the $1 / 4$ section (dashed lines) represented explicitly in the ANSYS modeling.

Figure 6. Influence of convection coefficient on temperatures of the clay block during a $4 \mathrm{~h}$ cooling after removal from the $43.3{ }^{\circ} \mathrm{C}$ oven.

Figure 7. Influence of convection coefficient on temperatures of the plywood backing during a $4 \mathrm{~h}$ cooling after removal from the $43.3{ }^{\circ} \mathrm{C}$ oven 10

Figure 8. Influence of convection coefficient on temperatures of the steel frame during a $4 \mathrm{~h}$ cooling after removal from the $43.3^{\circ} \mathrm{C}$ oven.

Figure 9. Comparison of ANSYS predicted and measured temperatures (October 2007 data) for the clay block in the test setup. Two separate sets of experimental data measured on two different days are plotted to provide an indication of variability

Figure 10. Measured thermocouple temperatures for the case of removing an equilibrated clay box test setup from the oven and monitoring its cooling (in the lab) over the course of $6 \mathrm{~h}$.

Figure 11. Measured and simulated temperatures for center of clay block (thermocouples J01 and J02) cooled for $6 \mathrm{~h}$ after removal from oven.

Figure 12. Measured and simulated temperatures for thermocouples J03, J04, and J05 embedded in clay block during $6 \mathrm{~h}$ of cooling after removal from oven.

Figure 13. Measured and simulated temperatures for thermocouples J06 and J07 embedded in clay block during $6 \mathrm{~h}$ of cooling after removal from oven.

Figure 14. Measured and simulated temperatures for center of clay block (thermocouples J01 and J02) heated for $16 \mathrm{~h}$ in the oven. 
Figure 15. Measured and simulated temperatures for thermocouples J03, J04, and J05 embedded in clay block during $16 \mathrm{~h}$ of heating in the oven.

Figure 16. Measured and simulated temperatures for thermocouples J06 and J07 embedded in clay block during $16 \mathrm{~h}$ of heating in the oven.

Figure 17. Measured thermocouple temperatures for the case of removing an equilibrated clay box test setup from the oven and monitoring its cooling over the course of $1 \mathrm{~h}$, followed by its reheating over the course of $16 \mathrm{~h}$.

Figure 18. Standard deviation for the seven measured thermocouple temperatures as a function of time. 18

Figure 19. Measured and simulated temperatures for center of clay block (thermocouples J01 and J02) first cooled for $1 \mathrm{~h}$ and then (re)heated for $4 \mathrm{~h}$ in the oven.

Figure 20. Measured and simulated temperatures for thermocouples J03 and J04 when clay block test setup is first cooled for $1 \mathrm{~h}$ and then (re)heated for $4 \mathrm{~h}$ in the oven.

Figure 21. Measured and simulated temperatures for thermocouples J06 and J07 when clay block test setup is first cooled for $1 \mathrm{~h}$ and then (re)heated for $4 \mathrm{~h}$ in the oven.

Figure 22. Comparison of predicted temperatures for thermocouples J01 and J02 for steel and aluminum frame clay block test setup geometries.

Figure 23. Comparison of predicted temperatures for thermocouples J03 and J04 for steel and aluminum frame clay block test setup geometries.

Figure 24. Comparison of predicted temperatures for thermocouples J06 and J07 for steel and aluminum frame clay block test setup geometries.

Figure 25. Predicted metal frame temperatures for the cases of aluminum and steel frames.

Figure 26. Comparison of clay temperatures for thermocouples J01 and J02 for uninsulated and insulated steel frames.

Figure 27. Comparison of clay temperatures for thermocouples J03, J04, and J05 for uninsulated and insulated steel frames.

Figure 28. Comparison of clay temperatures for thermocouples J06 and J07 for uninsulated and insulated steel frames.

Figure 29. Comparison of steel face and interface temperatures for uninsulated and insulated steel frames.

Figure 30. Predicted temperatures for small cylindrical clay specimen cooling from $43.3{ }^{\circ} \mathrm{C}$ in a laboratory at $20^{\circ} \mathrm{C}$. 
Figure 31. Predicted temperatures for small cylindrical clay specimen cooling from $60{ }^{\circ} \mathrm{C}$ in a laboratory

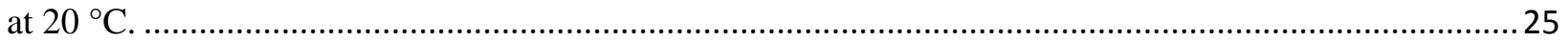




\section{List of Tables}

Table 1. Measured Thermal Conductivities of Plastilina ....................................................................... 5

Table 2. Measured Heat Capacities of Plastilina ................................................................................ 6

Table 3. Thermal Properties of Materials to be Employed in Thermal Modeling ...................................... 6 


\section{Introduction}

One of the steps in a program to evaluate the performance of hard and soft body armor is to place a clay box behind the material being tested [1,2]. After firing, the penetration depth into the clay is measured as a metric of performance. Conventionally, the clay box consists of a molded $610 \mathrm{~mm}$ by $610 \mathrm{~mm}$ by $140 \mathrm{~mm}$ (24 in x 24 in x $5.5 \mathrm{in}$ ) block of Roma Plastilina \# $1^{1}$ (modeling clay) with a $19 \mathrm{~mm}(3 / 4$ ") plywood backing and either a steel or an aluminum frame. Within the Law Enforcement Standards Office (OLES) at the National Institute of Standards and Technology (NIST), the steel frame is composed of a $3.175 \mathrm{~mm}(1 / 8$ ") thick U-channel.

Over time, the rheological and viscoelastic properties of the manufactured Plastilina have changed, such that the standard operating procedure now requires that the clay box be preconditioned in an oven at $43.3{ }^{\circ} \mathrm{C}\left(110^{\circ} \mathrm{F}\right)$ prior to being removed for the active testing phase. Immediately upon removed from the oven, the performance of the clay box is first validated by a series of calibration drops using a steel sphere drop weight. If the indentations produced by the drop weight are within the acceptance criteria, the test box is then utilized in actual ballistics tests. According to the National Institute of Justice (NIJ) 0101.06 standard [3], the drop test needs to be repeated after the actual ballistic tests. However, under other testing protocols, the calibration drops typically are not repeated after the tests, raising the question as to whether the unavoidable cooling of the clay box after removal from the oven affected the test results. A related question is how uniform the front surface temperature of the clay remains during cooling/testing. In this regard, the current testing protocol suggests that test shots not be fired near the periphery of the clay box testing frame.

The purpose of the present report is therefore two-fold: to develop a database of the thermophysical properties of the materials employed in the clay box construction and to utilize these properties in three-dimensional finite element simulations of the thermal performance of the clay box during cooling and heating. The thermophysical properties assessed included density, heat capacity, thermal conductivity, and emissivity. The three-dimensional simulations were conducted using ANSYS ${ }^{1}$ software [4]. Simpler approaches such as a lumped heat capacity analysis or an infinite plate one-dimensional solution (Heisler temperature charts [5]) were also explored. Finally, potential improvements in the homogeneity of the clay surface temperature distribution via the incorporation of a thin layer (frame) of polymeric foam insulation are also investigated via simulation.

\footnotetext{
${ }^{1}$ Certain commercial products are identified in this report to specify the materials used and procedures employed. In no case does such identification imply endorsement by the National Institute of Standards and Technology, nor does it indicate that the products are necessarily the best available for the purpose.
} 


\section{Materials and Methods}

A supply of Plastilina blocks was obtained from the manufacturer. While most measurements were performed on the blocks in this as received condition, a subset of the blocks was heated in a $40{ }^{\circ} \mathrm{C}$ oven and 'worked' by kneading by hand to mimic the environmental and mechanical loads experienced by the blocks during and following introduction into the clay box set up. An additional set of Plastilina specimens was obtained from the clay in a box that had been actively employed in service for a number of months and was being exchanged for new clay as part of a regular maintenance schedule. Scrap pieces of the plywood that were used as a backing material for the clay box were cut into two $100 \mathrm{~mm}$ x $100 \mathrm{~mm}$ pieces. The thermophysical properties of these pieces were measured both before and after aging in the $40{ }^{\circ} \mathrm{C}$ oven. For measurements of heat capacity (to be described subsequently), cylindrical (disk) specimens, nominally $18 \mathrm{~mm}$ in diameter, were extracted from the Plastilina and plywood blocks using a cork bore and a hole drill, respectively. Typical thermophysical properties for stainless steel, aluminum, and polystyrene insulation were obtained from the literature. Unless indicated otherwise below, all property measurements were conducted in laboratories maintained at $23{ }^{\circ} \mathrm{C} \pm 2{ }^{\circ} \mathrm{C}$.

\subsection{Density}

The density of each of the plywood blocks was determined by separate measurements of its mass, using a laboratory scale, and its three major dimensions, using a pair of digital calipers. While this same approach was attempted for the Plastilina blocks, an accurate measurement of dimensions was difficult due to their higher deformability. Thus, a volumetric flask method was employed where small spheres (balls of about $5 \mathrm{~mm}$ in diameter) of the Plastilina were used to displace water in a volumetric flask. Knowing the mass of the Plastilina spheres that were added to the flask, along with the displaced volume, the density of the Plastilina was easily calculated. Two separate measurements were performed to provide an indication of variability.

\subsection{Thermal Conductivity}

Thermal conductivities of the Plastilina and plywood were measured using a Hot Disk Thermal Constants Analyzer ${ }^{1}$. The basic configuration for making thermal measurements using this equipment is shown in Figure 1. The configuration implements a transient plane source technique [6,7], based on monitoring the decay of a thermal (electrical) pulse of known power and duration. It has been successfully applied to a variety of building materials, including fire resistive materials [8,9], cement pastes [10], and concrete [11]. For the current study, a 6.403 $\mathrm{mm}$ radius probe ( $\mathrm{Ni}$ foil encased in Kapton) was employed. The probe was sandwiched horizontally between twin specimens of either Plastilina or plywood as shown in Figure 1. After an equilibration time of at least $45 \mathrm{~min}$ in a laboratory nominally maintained at $23{ }^{\circ} \mathrm{C}$, measurements were obtained with a power of $0.3 \mathrm{~W}$ applied for a measurement time of $20 \mathrm{~s}$. The measured response of the probe/sensor was analyzed using the built-in software to determine the thermal conductivity of the specimens. The analyzer sampled 200 points during the $10 \mathrm{~s}$ measurement time, with points 100 to 160 typically being used for the quantitative analysis. 
While standard deviations in the measurements are reported in the results, according to the manufacturer, the thermal conductivity measurements performed in this manner are reproducible within $\pm 2 \%$.

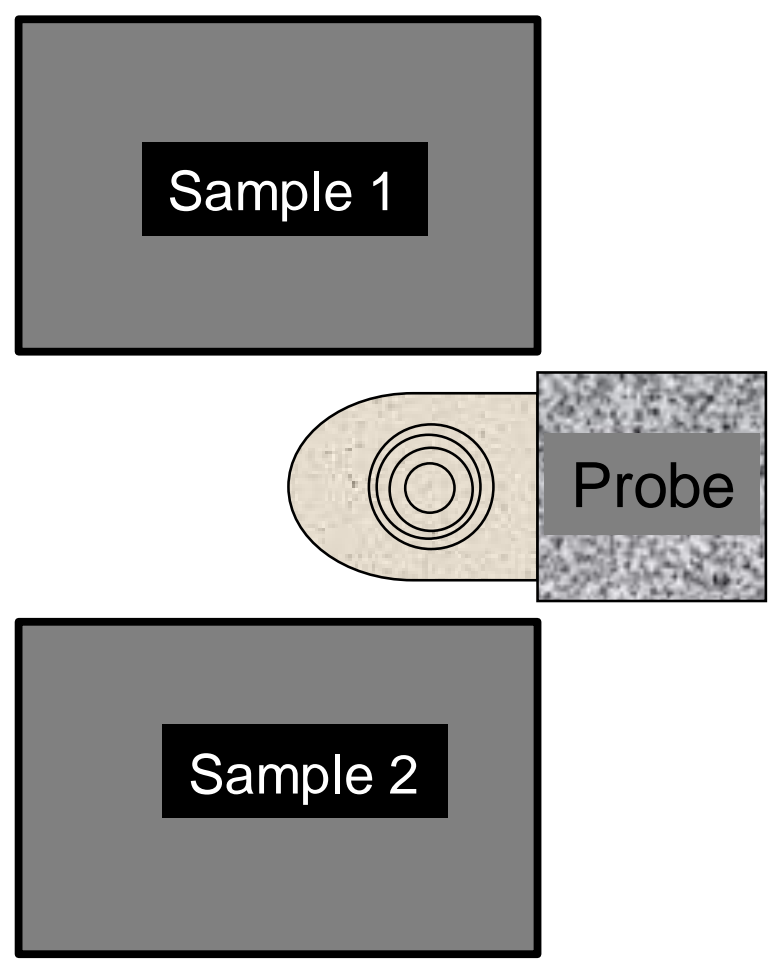

Figure 1. Basic configuration for measuring thermal properties using the Hot Disk Thermal Constants Analyzer.

\subsection{Heat Capacity}

For measurements of heat capacity, the cylindrical disks of either plywood or Plastilina of known mass (typically $1.5 \mathrm{~g}$ to $2.0 \mathrm{~g}$ ) were placed in the Hot Disk heat capacity unit, consisting of a special probe attached to the base of a gold pan/lid. For the measurements, the gold pan with its lid is surrounded on all sides by polystyrene insulation, in an attempt to minimize energy loss. First, a reference measurement is made with an empty pan (and lid), followed by the measurement with the specimen placed in the pan. For these heat capacity measurements, a power of $0.1 \mathrm{~W}$ was applied for a measurement time of $80 \mathrm{~s}$. In this case, points 100 to 200 (of the total 200 sampled in the $80 \mathrm{~s}$ test period) were used in the quantitative analysis. Knowing the mass of the specimen, its heat capacity in units of $\mathrm{J} /(\mathrm{g} \cdot \mathrm{K})$ can be easily determined. The heat capacity measurements were facilitated by assuring that the specimen surface contacting the bottom of the pan was nominally flat to produce a high quality (thermal) contact between pan and sample. Additionally, the thickness of each specimen was controlled, at about $4 \mathrm{~mm}$, such that the top of the specimen did not contact the bottom surface of the gold lid, as recommended in the Hot Disk User's Manual. According to the manufacturer, the heat capacity measurements made in this manner are reproducible to within $\pm 2 \%$. 


\subsection{Emissivity}

To complete the thermophysical property characterization for the plywood and the Plastilina, their emissivities (or total reflectances) were measured using a Gier-Dunkle reflectometer $^{1}[12,13]$ that is available in the Engineering Laboratory at NIST. This equipment measures the reflectance from a flat specimen surface and is calibrated using a set of high reflectivity (polished gold metal) and a low reflectivity (same gold painted a flat black) standards, with known total reflectances of 0.955 and 0.089 , respectively. For the Plastilina, both original and oven aged/worked blocks of the material were evaluated. For emissivity, the plywood samples were only evaluated after thermal aging at $40{ }^{\circ} \mathrm{C}$.

\section{Modeling}

Once an adequate database of the thermophysical properties of the clay box component materials had been established, thermal modeling was conducted using a variety of approaches. The simplest approach utilized a lumped heat capacity analysis [5], in which it is assumed that the thermal conductivities of all component materials are high enough that heat transfer to the environment is controlled by the thermal capacities of the materials and the convection heat transfer coefficient, $h$. In this case, the (assumed) spatially uniform temperature, $T$, of the system at time, $\tau$, is given by:

$$
\left(T-T_{\infty}\right) /\left(T_{0^{-}} T_{\infty}\right)=\exp \left\{(-h A \tau) /\left[\sum\left(\rho_{i} C_{i} V_{i}\right)\right]\right\}
$$

where $T_{\infty}$ is the ambient (environment) temperature, $T_{0}$ is the initial temperature of the clay box, $A$ is the exposed surface area, $\tau$ is elapsed time, $\rho$ is density, $C$ is heat capacity, and $V$ is volume. The product of these latter three terms for each material (Plastilina block, plywood backing, and metal frame) is included in a summation to determine the total thermal capacity of the clay box. It is recommended that a lumped heat capacity analysis only be applied when the quantity $h(V / A) / k$, where $k$ is thermal conductivity, is less than 0.1 [5]. In this and all subsequent analyses, adequate knowledge of the convection heat transfer coefficient is a requisite for making reasonable predictions of real world performance. One commonly employed relationship for estimating $h$ under laminar flow conditions, in units of $\mathrm{W} /\left(\mathrm{m}^{2} \cdot \mathrm{K}\right)$ is [5]:

$$
h=1.42(\Delta T / L)^{1 / 4}
$$

where $\Delta T$ is the temperature difference in ${ }^{\circ} \mathrm{C}$ and $L$ is a representative length of the specimen, such as the height of the clay box in this case. While this lumped heat capacity approach may be too simplified to be valid in practice for the clay box, it still can be used to examine the effects of the plywood backing and metal frames (aluminum or steel) on the temperature history of the composite system.

The major limitation of the lumped heat capacity analysis is that it assumes that the temperatures of the materials will not be a function of depth, which is quite unlikely since the clay box is about $140 \mathrm{~mm}$ thick and the clay itself is only moderately thermally conductive. This

variation in temperature with thickness can be considered first in a one-dimensional transient 
heat transfer analysis that considers the Plastilina block itself as an infinite plate of fixed thickness. Solutions to this problem, in graphical form, were first derived by Heisler [14] and later reprinted in a general heat transfer text [5]. The latter were utilized in this study to determine center and surface temperatures for a Plastilina block of $140 \mathrm{~mm}$ thickness. This analysis still ignores the contributions of the plywood backing and the metal frame to the heat transfer. However, it does provide a convenient check of the modeling in ANSYS for an equivalent (Plastilina block only) system.

The final type of thermal modeling employed in the present study was full scale threedimensional modeling of the clay box using the Thermal Analysis Package of the ANSYS Mechanical APDL software [4]. In general, steps for conducting an ANSYS analysis consist of creating a database of material properties, constructing the specimen geometry as a set of component volumes, assigning material properties to the created volumes, meshing the volumes, creating appropriate 'contact pairs' to link component interfaces, assigning convective and adiabatic boundaries, assigning initial conditions (temperatures), executing the analysis, and processing the results. Appendix A provides detailed step-by-step instructions for one of the ANSYS executions actually employed in the present study.

\section{Results}

\subsection{Thermophysical Properties}

As mentioned previously, for the Plastilina, a variety of specimens were obtained and subjected to measurements with the thermal constants analyzer. For measurements of thermal conductivity using a twin set of specimens configured at various orientations, the obtained results are summarized in Table 1 that provides the mean values of thermal conductivity and their coefficients of variation, all measured at $23{ }^{\circ} \mathrm{C} \pm 2{ }^{\circ} \mathrm{C}$. For the small cylindrical specimens employed for heat capacity determinations, the results can be found in Table 2. There was much less variability in the heat capacities of the various classes of Plastilina specimens than in their thermal conductivities. For the purposes of the thermal modeling, a thermal conductivity value of $0.6 \mathrm{~W} /(\mathrm{m} \cdot \mathrm{K})$ and a heat capacity of $1280 \mathrm{~J} /(\mathrm{kg} \cdot \mathrm{K})$ were selected as the best (conservative) estimates for these two thermal properties for Plastilina (Table 3). Using the volumetric flask method, the density of Plastilina was measured to be $1570 \mathrm{~kg} / \mathrm{m}^{3} \pm 8 \mathrm{~kg} / \mathrm{m}^{3}$, based on two replicates. Using the Gier-Dunkle reflectometer, the emissivity of the Plastilina block was measured as $0.895 \pm 0.002$ in its as received state and $0.888 \pm 0.001$ after thermal aging.

Table 1. Measured Thermal Conductivities of Plastilina

\begin{tabular}{|c|c|c|c|}
\hline Material & $\begin{array}{c}\text { Number of } \\
\text { replicates }\end{array}$ & $\begin{array}{c}\text { Mean thermal } \\
\text { conductivity } \\
{[\mathrm{W} /(\mathrm{m} \cdot \mathrm{K})]}\end{array}$ & $\begin{array}{c}\text { Coefficient of Variation } \\
(\%)\end{array}$ \\
\hline Block 1 (2010) & 20 & 0.593 & $6.8 \%$ \\
\hline Block 1 aged at 40 ${ }^{\circ} \mathrm{C}$ & 5 & 0.555 & $1.7 \%$ \\
\hline Aged block worked by hand & 9 & 0.549 & $2.1 \%$ \\
\hline Extracted from used test setup & 9 & 0.524 & $2.3 \%$ \\
\hline Block 2 (2011) & 14 & 0.538 & $7.6 \%$ \\
\hline
\end{tabular}


Table 2. Measured Heat Capacities of Plastilina

\begin{tabular}{|c|c|c|c|}
\hline Material & $\begin{array}{c}\text { Number of } \\
\text { replicates }\end{array}$ & $\begin{array}{c}\text { Mean heat capacity } \\
{[\mathrm{J} /(\mathrm{kg} \cdot \mathrm{K})]}\end{array}$ & $\begin{array}{c}\text { Coefficient of Variation } \\
(\%)\end{array}$ \\
\hline Block 1 (2010) & 12 & 1280 & $2.6 \%$ \\
\hline Block 1 aged at $40^{\circ} \mathrm{C}$ & 5 & 1260 & $1.2 \%$ \\
\hline Extracted from used test setup & 3 & 1270 & $0.3 \%$ \\
\hline Block 2 (2011) & 5 & 1320 & $1.0 \%$ \\
\hline
\end{tabular}

Two small plywood specimens were used to construct the sandwich geometry for the thermal conductivity measurements. Before thermal aging at $40{ }^{\circ} \mathrm{C}$, the measured value was $0.152 \mathrm{~W} /(\mathrm{m} \cdot \mathrm{K}) \pm 0.009 \mathrm{~W} /(\mathrm{m} \cdot \mathrm{K})$, for nine replicate measurements. After thermal aging, the measured value was $0.146 \mathrm{~W} /(\mathrm{m} \cdot \mathrm{K}) \pm 0.005 \mathrm{~W} /(\mathrm{m} \cdot \mathrm{K})$ for five replicate measurements. For the plywood, a mean heat capacity of $1410 \mathrm{~J} /(\mathrm{kg} \cdot \mathrm{K})$ was measured with a coefficient of variation of $2 \%$ for seven replicates on a single cylindrical specimen. After thermal aging, based on measurements of mass and dimension, its density was determined to be $540 \mathrm{~kg} / \mathrm{m}^{3} \pm 10 \mathrm{~kg} / \mathrm{m}^{3}$ (two replicate blocks). For the plywood, after thermal aging at $40{ }^{\circ} \mathrm{C}$, an emissivity of $0.906 \pm 0.001$ was obtained using the Gier-Dunkle reflectometer. Based on these measurements, the values shown in Table 3 were selected as representative thermophysical properties for the plywood employed in the ballistic clay test setup. For comparison purposes, a Lawrence Berkeley National Laboratory online database [15] provides values of $0.12 \mathrm{~W} /(\mathrm{m} \cdot \mathrm{K})$, $1210 \mathrm{~J} /(\mathrm{kg} \cdot \mathrm{K})$, and $540 \mathrm{~kg} / \mathrm{m}^{3}$ for the thermal conductivity, heat capacity, and density of plywood, respectively.

Table 3. Thermal Properties of Materials to be Employed in Thermal Modeling

\begin{tabular}{|c|c|c|c|}
\hline Material & $\begin{array}{c}\text { Thermal conductivity } \\
{[\mathrm{W} /(\mathrm{m} \cdot \mathrm{K})]}\end{array}$ & $\begin{array}{c}\text { Heat capacity } \\
{[\mathrm{J} /(\mathrm{kg} \cdot \mathrm{K})]}\end{array}$ & $\begin{array}{c}\text { Density } \\
{\left[\mathrm{kg} / \mathrm{m}^{3}\right]}\end{array}$ \\
\hline Plastilina \#1 & 0.6 & 1280 & 1570 \\
\hline Plywood & 0.15 & 1410 & 540 \\
\hline Aluminum [16] & 215 & 910 & 2700 \\
\hline Stainless steel (AISI 304) [17] & 16 & 480 & 7920 \\
\hline Polystyrene insulation [18] & 0.03 & 1340 & 20 \\
\hline
\end{tabular}

\subsection{Thermal Modeling}

\section{Lumped Heat Capacity Analysis}

According to the dimensions provided in the Introduction section and the densities of the materials from Table 3, the computed mass of the clay box test setup should be about $100 \mathrm{~kg}$. Actual weighing of a setup at NIST yielded a value of $109 \mathrm{~kg}$, a difference of less than $10 \%$. This difference is most likely due to the steel "handles" located on the sides of the steel frame that were not considered in the modeled geometry. Based on the modeled geometry, the results of the simplified lumped heat capacity analysis are summarized in Figures 2 and 3. In Figure 2, a comparison of the predictions for just the clay, the clay and steel frame, and the complete experimental setup (clay, plywood, and steel frame) is provided, with equation (2) being utilized 


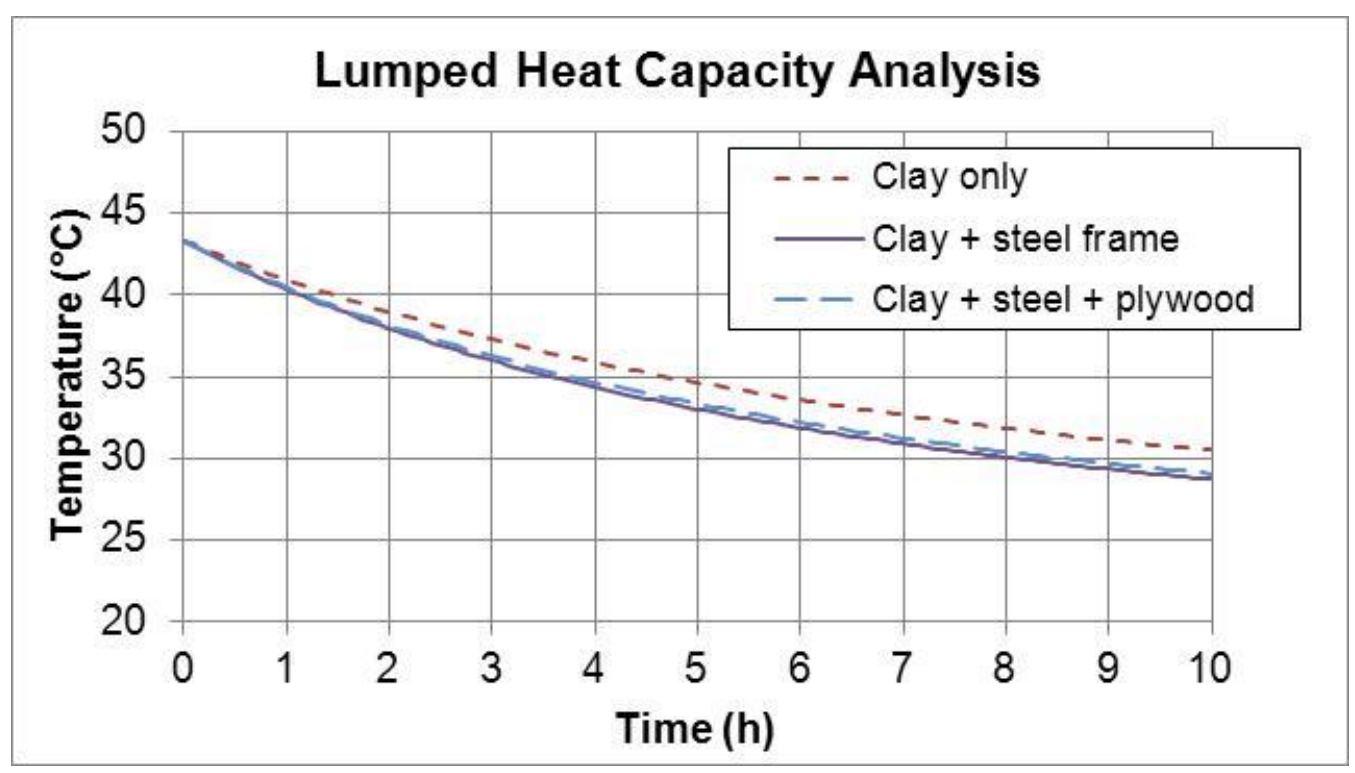

Figure 2. Predictions for system temperature via lumped heat capacity analysis with a variable natural convection heat transfer coefficient, $h$.

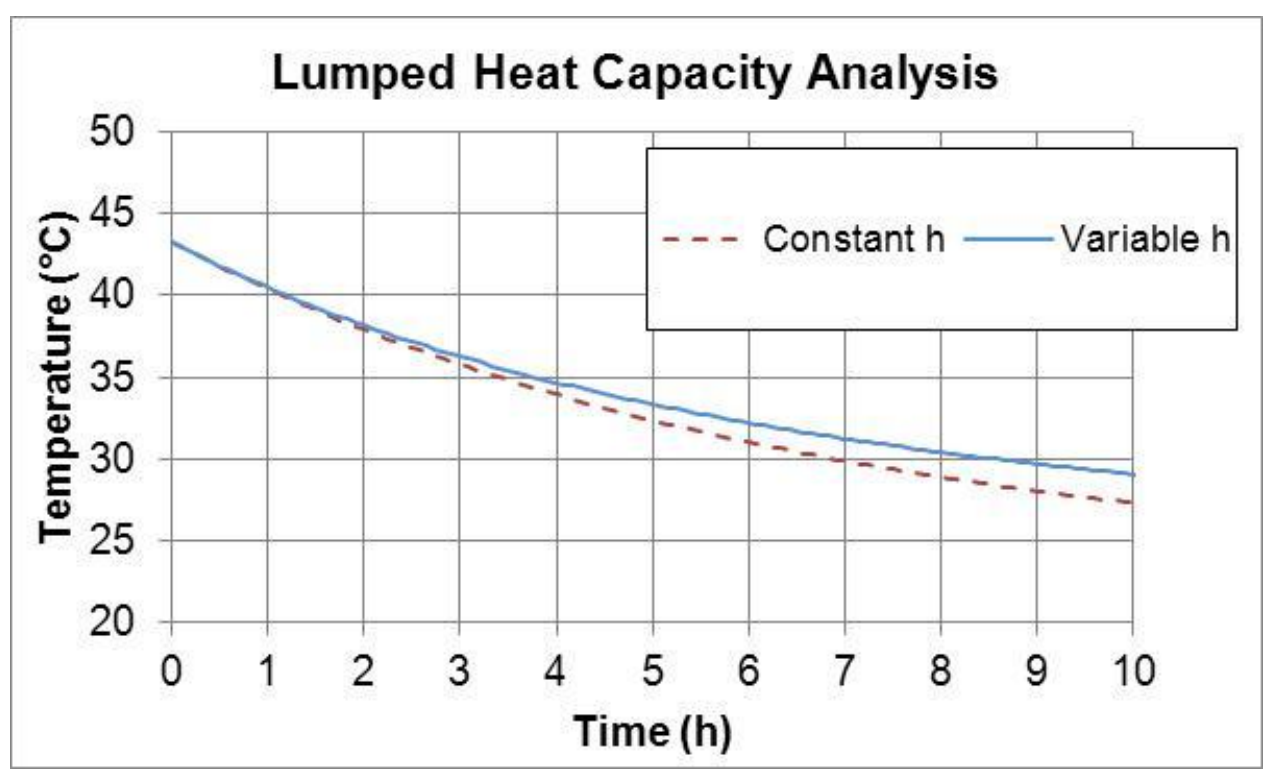

Figure 3. Comparison of lumped heat capacity analysis predictions for the clay/plywood/steel frame test setup for the cases of constant and variable natural convection heat transfer coefficients.

to update the natural convection heat transfer coefficient throughout the course of the computation. In Figure 3, a comparison is provided for the complete experimental setup for the cases of utilizing either a constant (for $\Delta T=20^{\circ} \mathrm{C}$ ) or a variable natural convection heat transfer coefficient (via equation (2) once again). From the preliminary and simplified analysis contained in these two figures, the following important conclusions can be reached: 
1) Based on the results in Figure 2, the overall temperature of the cooling clay box test setup is dominated by the behavior of the clay itself, mainly due to its much larger (thermal) mass in comparison to the plywood and metal frame components of the system.

2) Based on the results in Figure 3, for predictions out through two hours, there is little difference between assuming a constant value for the convection heat transfer coefficient and adjusting it based on temperature according to equation (2). Based on this conclusion, for the ANSYS simulations to follow, a constant convection heat transfer coefficient value will be assumed for a given 3-D simulation.

\section{Heisler Chart Analysis}

Using the measured thermophysical properties of the Plastilina clay, a one-dimensional Heisler analysis was conducted to predict both the center and face temperatures of the clay block. These values were then compared to the values predicted at the central axis in a complete 3-D ANSYS analysis. As shown in Figure 4 for a simulation time of $6 \mathrm{~h}$, the comparison is quite favorable, lending some credibility to the 3-D simulations being executed in ANSYS for the remainder of the thermal modeling process.

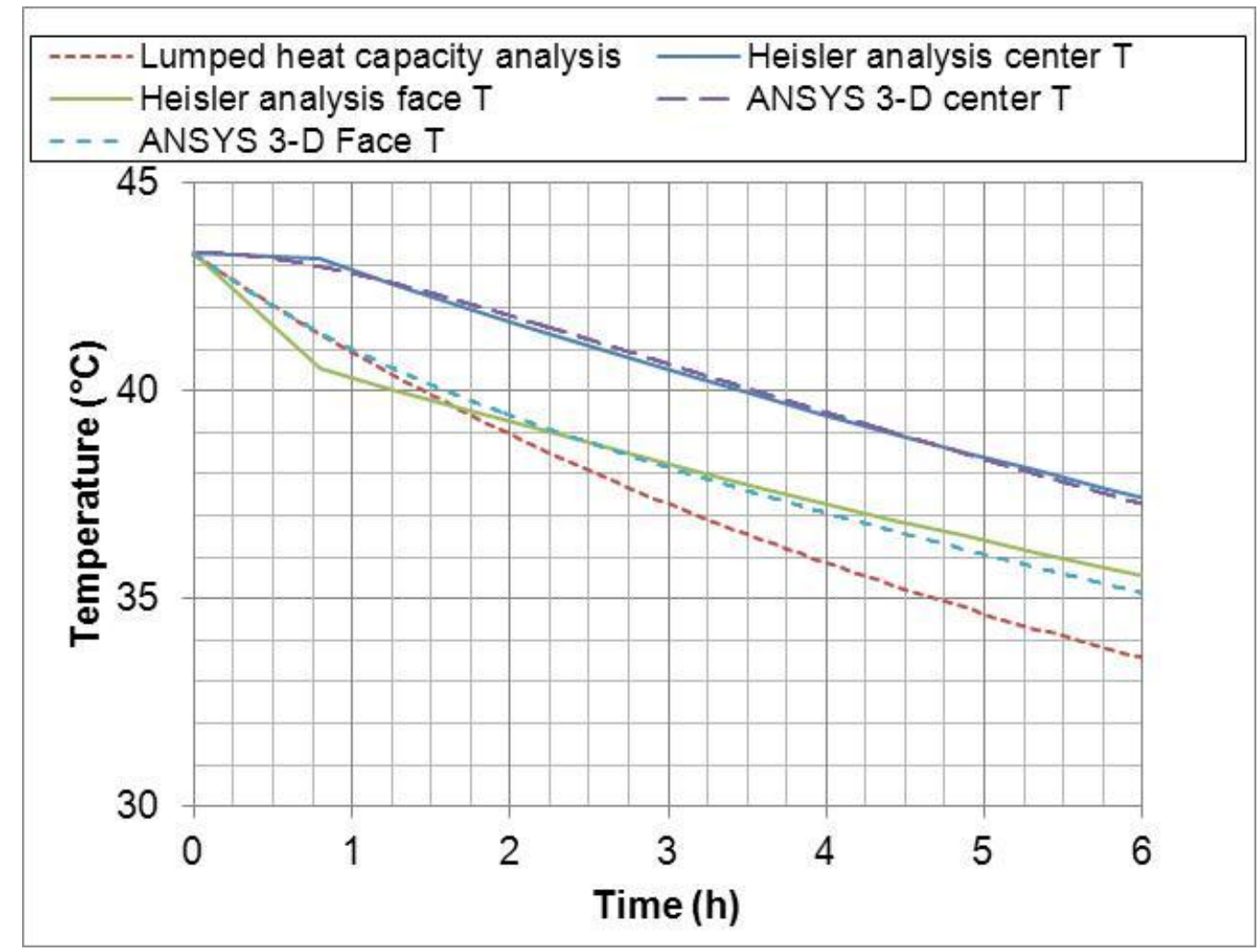

Figure 4. Comparison of lumped heat capacity, Heisler, and ANSYS analyses for the case of only the clay block cooling after removal from the oven. 


\section{ANSYS 3-D Simulations}

The ANSYS three-dimensional simulations were conducted to evaluate the influence of a variety of parameters on the temperature history of the cooling clay box setup. In general, simulations were conducted to model a $4 \mathrm{~h}$ to $6 \mathrm{~h}$ cooling period, using a $1 / 4$ section of the overall system volume to take advantage of its inherent symmetries (Figure 5). Adiabatic boundaries are then applied at the central axes due to their mirror symmetries. Following the simulation, various points within the clay, plywood, and metal frame or near the interfaces between two of these were selected for graphical analysis.

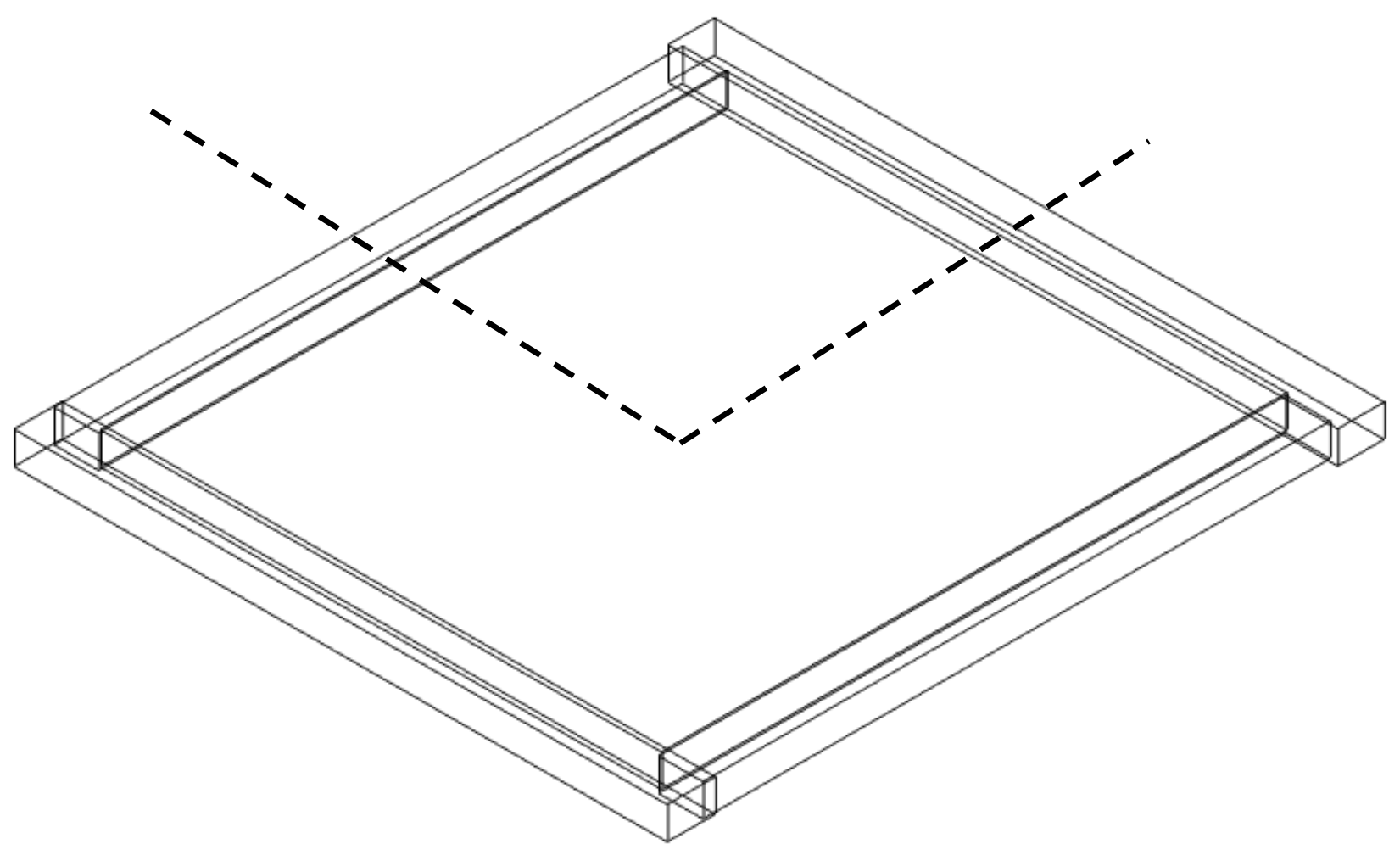

Figure 5. 3-D representation of metal frame around the clay block, showing the $1 / 4$ section (dashed lines) represented explicitly in the ANSYS modeling.

The first parametric study focused on the influence of the value (constant with time) assigned to the heat transfer coefficient, $h$, for all exposed surfaces. Based on the expected range of plausible values for this parameter, simulations were first conducted with values of $1 \mathrm{~W} /\left(\mathrm{m}^{2} \cdot \mathrm{K}\right)$, $3 \mathrm{~W} /\left(\mathrm{m}^{2} \cdot \mathrm{K}\right)$, or $5 \mathrm{~W} /\left(\mathrm{m}^{2} \cdot \mathrm{K}\right)$. For this parametric study, three points were selected for monitoring temperatures for the clay: 1) a point exactly at the center of the clay block volume (center $), 2)$ a point exactly in the center of the exposed face (face), and 3) a point on the exposed face of the clay block at one of its corners (corner). For the plywood, points were chosen at the center of its exposed face (plywoodface), at the center of its volume (plywoodcenter), and at the center of the interface with the clay block (plywoodclay). For the metal frame, points were chosen at the center of the exposed face of one of the four framing bars (steel_face) and at the center of one its interfaces with the clay block (steel_clay). As shown in Figures 6 to 8, the choice of the convection coefficient has a dramatic effect on the temperature response of each material in the 
clay box test setup. Since all three materials, clay, plywood, and metal (steel) frame, have one or more of their faces exposed directly to the external environment, the temperatures within each are strongly influenced by the selected convection heat transfer coefficient.

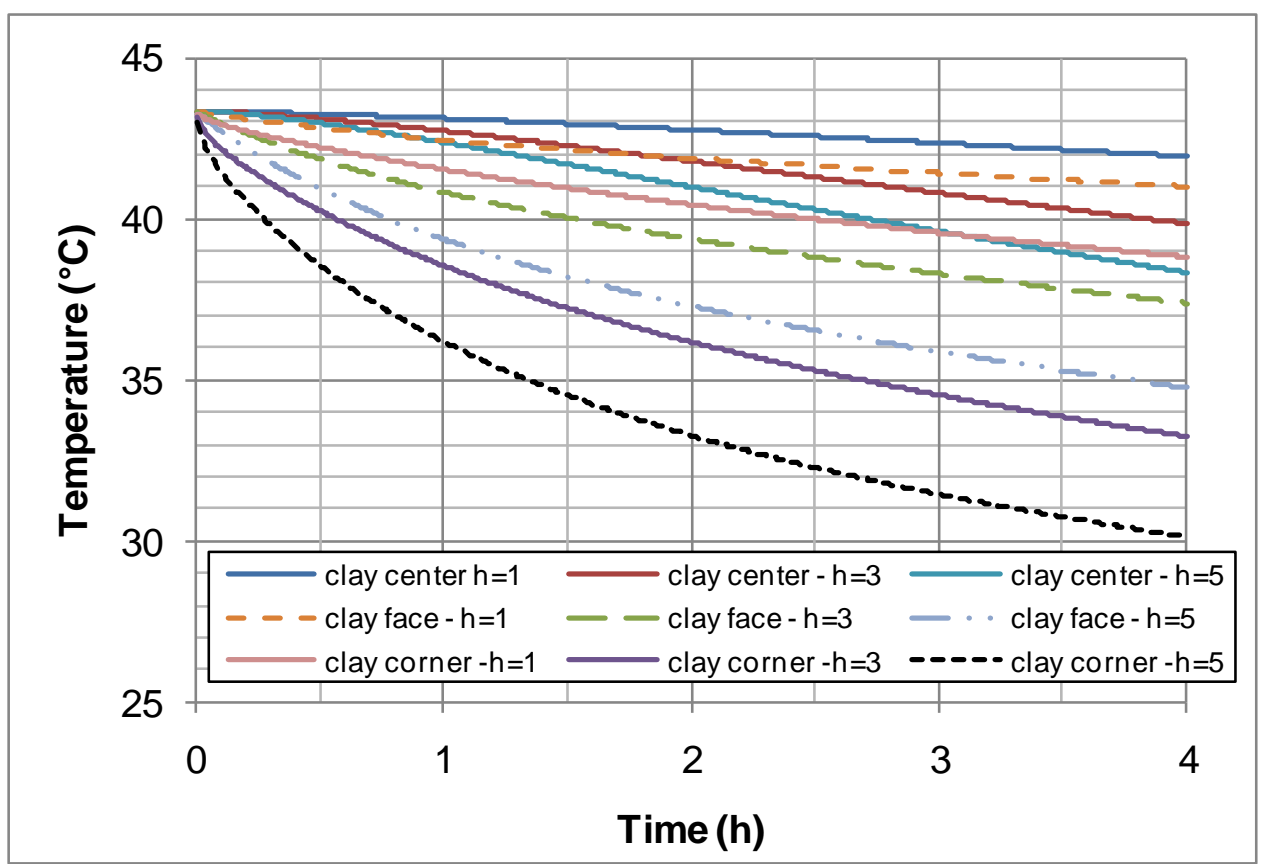

Figure 6. Influence of convection coefficient on temperatures of the clay block during a $4 \mathrm{~h}$ cooling after removal from the $43.3{ }^{\circ} \mathrm{C}$ oven.

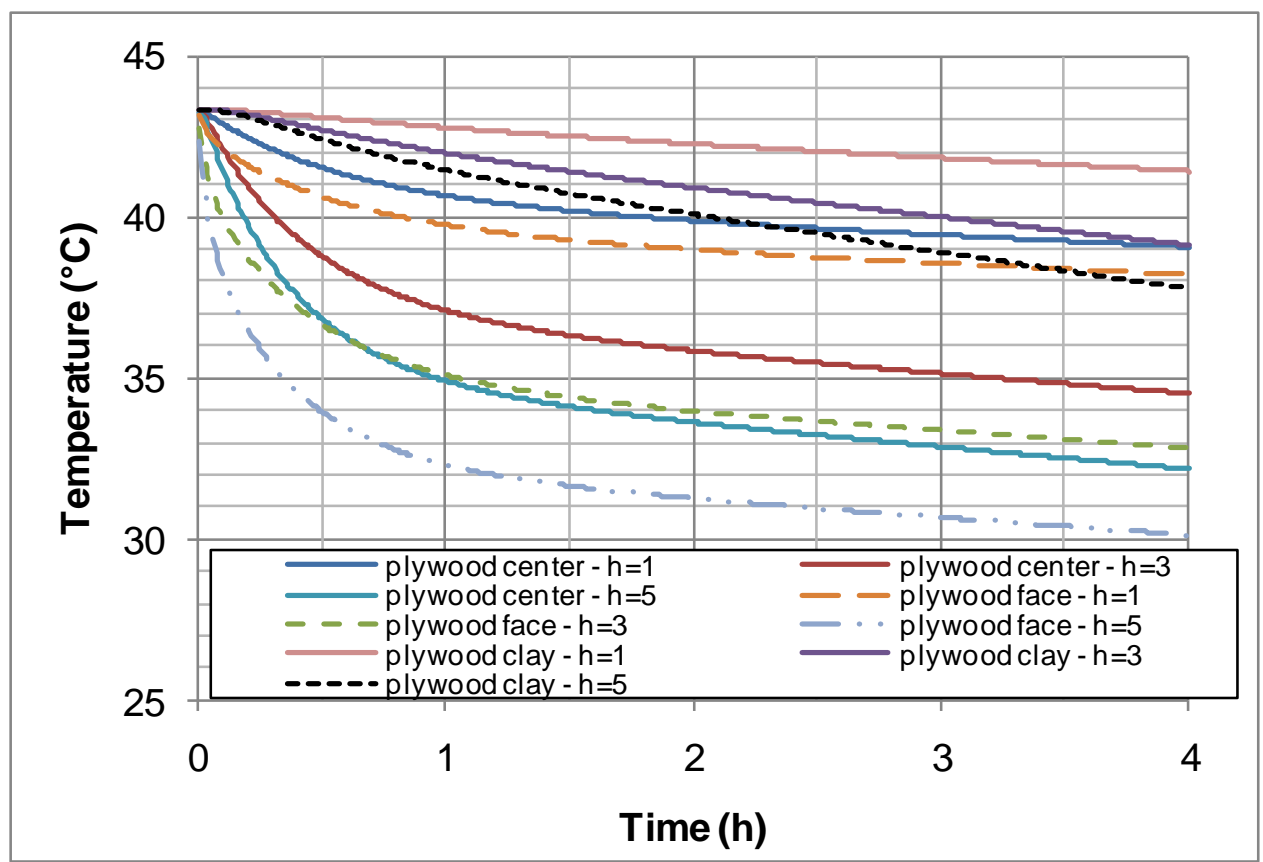

Figure 7. Influence of convection coefficient on temperatures of the plywood backing during a $4 \mathrm{~h}$ cooling after removal from the $43.3{ }^{\circ} \mathrm{C}$ oven. 


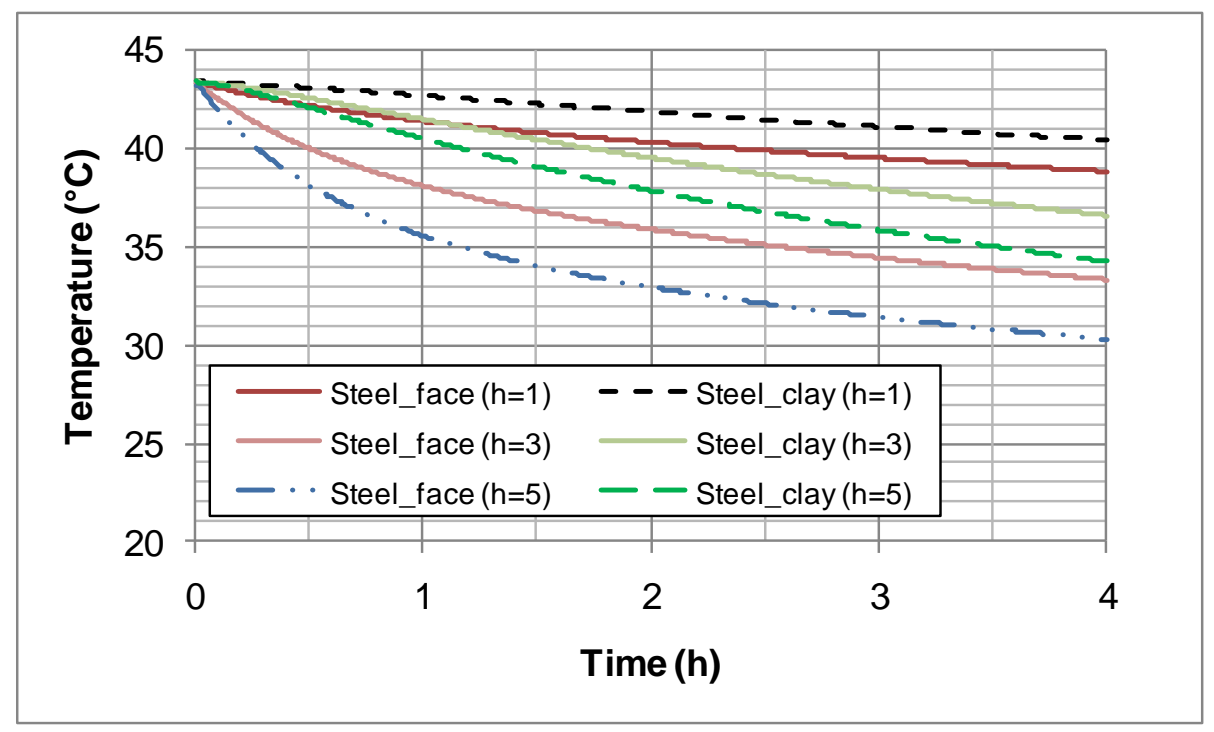

\section{Figure 8. Influence of convection coefficient on temperatures of the steel frame during a $4 \mathrm{~h}$ cooling after removal from the $43.3{ }^{\circ} \mathrm{C}$ oven.}

In each case, the clay face corner temperature is much less than the clay face center temperature because of its contact with the high thermal conductivity metal frame. For example, for the case of $h=5 \mathrm{~W} /\left(\mathrm{m}^{2} \cdot \mathrm{K}\right)$, after $1 \mathrm{~h}$ of cooling, the temperature of the clay face at its center is about $39.5{ }^{\circ} \mathrm{C}$, while that of the corner face point is near $36{ }^{\circ} \mathrm{C}$. This temperature distribution supports the testing practice of not shooting bullets near the outer periphery of the clay block during body armor testing.

Since results vary widely with the selected value of $h$, the only realistic option is to calibrate this parameter by comparing simulation to actual measured temperatures during cooling of the test setup upon removal from the oven. Some measurements of the clay block temperature that were obtained in October of 2007 were first used for this purpose. In 2007, temperatures were measured at the center face of the clay block and about $150 \mathrm{~mm}$ off center, both about $25 \mathrm{~mm}$ deep into the block, at $20 \mathrm{~s}$ increments during the course of several hours. A comparison of this experimental data with the ANSYS simulations is provided in Figure 9. While the experimental measurements were performed at a depth of $25 \mathrm{~mm}$ into the clay block, these values were compared to the simulation values computed at the block surface, as the simulations indicated less than a $0.1{ }^{\circ} \mathrm{C}$ maximum difference between surface and $25 \mathrm{~mm}$ deep temperatures, for the specific case of $h=3 \mathrm{~W} /\left(\mathrm{m}^{2} \cdot \mathrm{K}\right)$. While the initial temperature in the center face of the block is slightly higher in the experimental cases than in the ANSYS simulation, the overall trends of the curves in Figure 9 clearly indicate that a choice of $5 \mathrm{~W} /\left(\mathrm{m}^{2} \cdot \mathrm{K}\right)$ for the convection heat transfer coefficient would be superior to one of $3 \mathrm{~W} /\left(\mathrm{m}^{2} \cdot \mathrm{K}\right)$. In fact, this former choice for $h$ provides quite a reasonable fit to the temperature data measured in 2007.

In the summer of 2011, further measurements of the clay box temperatures under a variety of heating (forced air oven) and cooling (lab) conditions were conducted at NIST. A set of eight thermocouples were employed, one to measure the air temperature near the clay block 


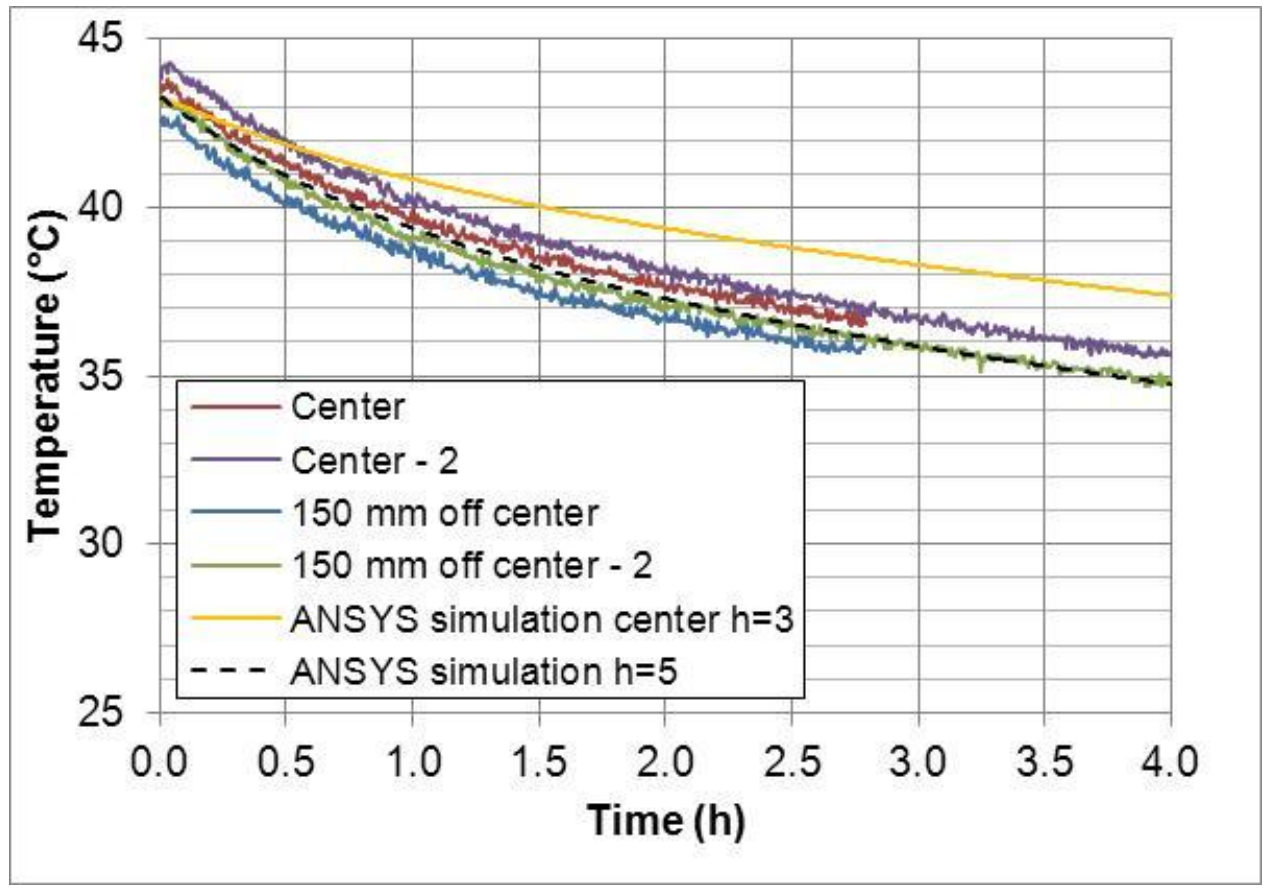

Figure 9. Comparison of ANSYS predicted and measured temperatures (October 2007 data) for the clay block in the test setup. Two separate sets of experimental data measured on two different days are plotted to provide an indication of variability.

and the other seven embedded at the following locations within the clay block:

1) Thermocouple $\mathbf{J 0 1}$ was positioned at the center of the clay block at a depth of approximately $16 \mathrm{~mm}$. In ANSYS system coordinates with units of meters, when modeling $1 / 4$ of the system as shown in Figure 5, this location would correspond to an $\mathrm{x}, \mathrm{y}, \mathrm{z}$ location of $(0,0,0.016)$.

2) Thermocouple $\mathbf{J 0 2}$ was positioned at this same central location but at a depth of approximately $70 \mathrm{~mm}$ (the middle of the clay thickness). This location would correspond to ANSYS coordinates of $(0,0,0.07)$.

3) Thermocouple $\mathbf{J 0 3}$ was positioned $152.4 \mathrm{~mm}$ from the top edge and $152.4 \mathrm{~mm}$ from the left side of the clay block at a depth of $13 \mathrm{~mm}$. Based on symmetry considerations, this location can be represented in the ANSYS simulation by a node located at the coordinates of $(0.1524,0.1524,0.013)$.

4) Thermocouple $\mathbf{J 0 4}$ was at the same $x, y$ location as $\mathbf{J 0 3}$, but at a depth of $70 \mathrm{~mm}$. Its coordinates are therefore $(0.1524,0.1524,0.07)$.

5) Thermocouple $\mathbf{J 0 5}$ was positioned $152.4 \mathrm{~mm}$ from the top edge on the vertical center line of the clay block, at a depth of approximately $13 \mathrm{~mm}$. Its coordinates would therefore be $(0,0.1524,0.013)$.

6) Thermocouple J06 was positioned approximately $25.4 \mathrm{~mm}$ from the top edge and $25.4 \mathrm{~mm}$ from the right side of the clay block at a depth of $13 \mathrm{~mm}$. It coordinates are thus $(0.2794,0.2794,0.013)$.

7) Thermocouple J07 was positioned at the same $\mathrm{x}, \mathrm{y}$ location as J06, but at a depth of $70 \mathrm{~mm}$. This thermocouple's coordinates are $(0.2794,0.2794,0.07)$. 
A variety of experiments were conducted employing these thermocouple locations. For example, an equilibrated (heated) clay box test setup was removed from the oven and its cooling monitored over the course of $6 \mathrm{~h}$. Thermocouple temperatures for this case are provided in Figure 10. It is clear from Figure 10 that the temperatures of the clay, in general, are significantly lower than those measured in the October 2007 study. This suggests that for the lab conditions present in the summer of 2011, the convection coefficient is likely higher than that present in the lab in October 2007. This could be attributed to differences in heating/cooling loads present in the lab (forced vs. natural convection), particularly as the outdoor temperatures were quite high in the summer of 2011 (being greater than $35^{\circ} \mathrm{C}$ on many days). Alternatively, the thermal properties of the 2007 clay may have been significantly different from those of the 2010-2011 clays, as the formulation of this material has been known to change over time.

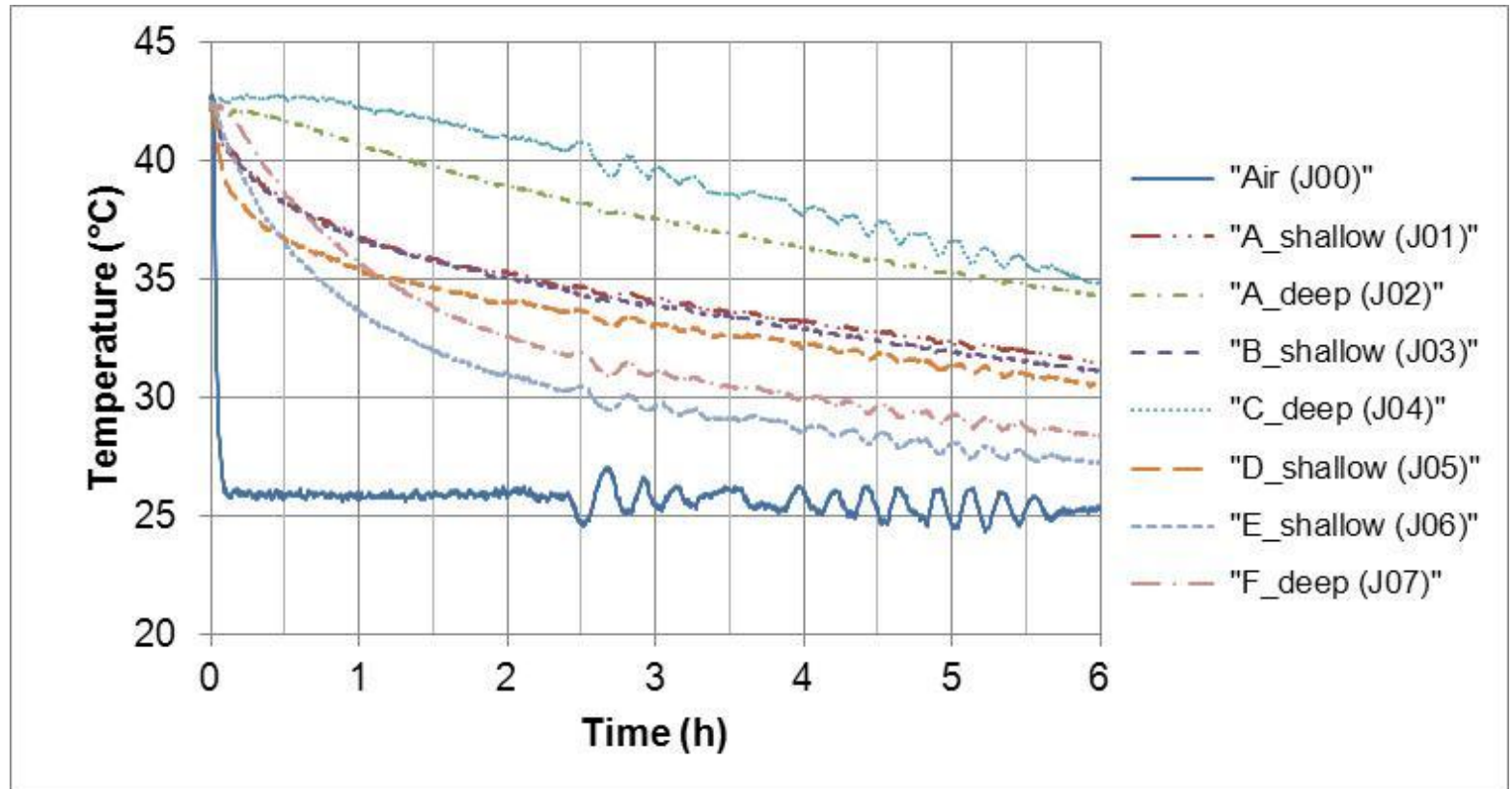

Figure 10. Measured thermocouple temperatures for the case of removing an equilibrated clay box test setup from the oven and monitoring its cooling (in the lab) over the course of $6 \mathrm{~h}$.

Since the current objective is to model the thermal performance of the current batch(es) of clay, the ANSYS simulations were "recalibrated" to the summer 2011 temperature measurements. For matching the central clay block temperatures (J01 and J02), a convection coefficient of $10 \mathrm{~W} /\left(\mathrm{m}^{2} \cdot \mathrm{K}\right)$ was found to provide a reasonable fit. However, with this single convection parameter, the fits for the other thermocouples were less than desirable. Since the steel frame is U-shaped, it provides additional surface area (relative to its being modeled in ANSYS as a simple rectangular prism) for convective transfer (similar to fins employed to increase heat transfer on electronic components for example). Based on this difference, the convection coefficient for the exposed steel surfaces in ANSYS was adjusted to a value of $15 \mathrm{~W} /\left(\mathrm{m}^{2} \cdot \mathrm{K}\right)$. Using these two convection coefficients, $10 \mathrm{~W} /\left(\mathrm{m}^{2} \cdot \mathrm{K}\right)$ for the exposed clay and plywood surfaces and $15 \mathrm{~W} /\left(\mathrm{m}^{2} \cdot \mathrm{K}\right)$ for the exposed steel surfaces, provided a reasonable fit to the experimentally measured temperatures for the cooling of an equilibrated (heated) specimen. 
For the $6 \mathrm{~h}$ cooling experiment (Figure 10), the average clay temperature when first removed from the oven was $42.3{ }^{\circ} \mathrm{C}$, while the average temperature measured for the laboratory air during the course of the experiment was $25.6{ }^{\circ} \mathrm{C}$. With these parameters employed in the ANSYS simulation, the results for thermocouples J01 to J07 shown in Figures 11, 12, and 13 were obtained. As can be seen in Figures 11-13, using this set of convection coefficients generally provided a reasonable agreement between the experimental data and the ANSYS predictions. Deviations between experimentally measured and ANSYS-predicted temperatures are generally less than $1{ }^{\circ} \mathrm{C}$, considered to be an acceptable agreement. The fits are also much better during the first hour of cooling (the time of most interest to real testing) than at later times.

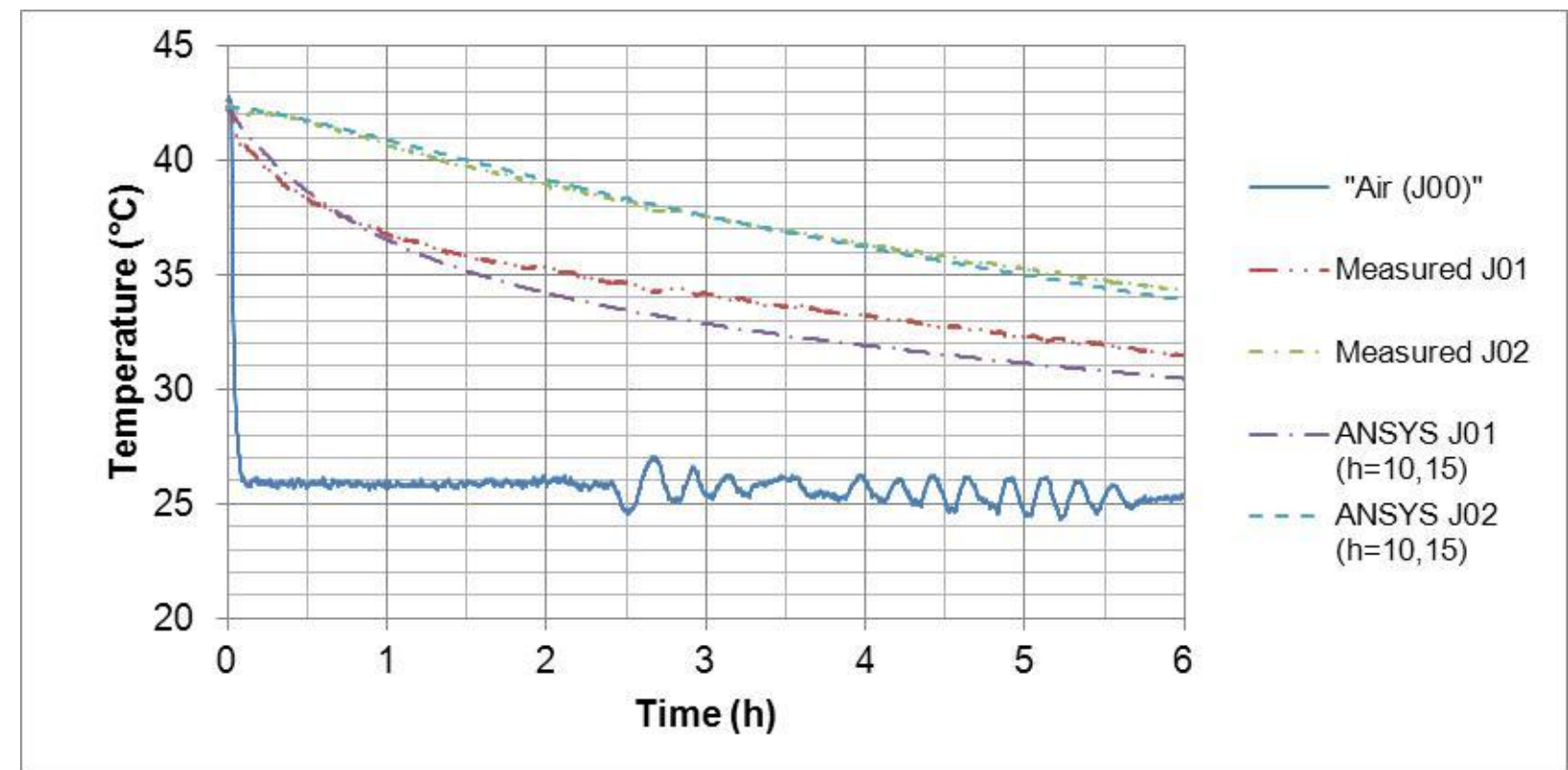

\section{Figure 11. Measured and simulated temperatures for center of clay block (thermocouples $\mathrm{J01}$ and J02) cooled for $6 \mathrm{~h}$ after removal from oven.}

Results of an ANSYS simulation were also compared to the experimental results for the case of the clay block test setup being placed in the oven after first being equilibrated to laboratory conditions. Here, the average oven temperature was measured to be $42.3{ }^{\circ} \mathrm{C}$, the initial average temperature of the clay block was $26.1{ }^{\circ} \mathrm{C}$, and the simulation was executed for $16 \mathrm{~h}$. In this case, the convection coefficient for the steel surfaces was further increased to $20 \mathrm{~W} /\left(\mathrm{m}^{2} \cdot \mathrm{K}\right)$ to provide a better agreement between simulation and experiment. After this adjustment, the comparison of simulation to experimental measurements, as shown in Figures 14 to 16, indicates an acceptable agreement, particularly for the thermocouples buried at mid-depth within the clay specimen. With the exception of the results for thermocouple J06, the ANSYS predictions are generally within $1{ }^{\circ} \mathrm{C}$ of their corresponding measured temperature values throughout the $16 \mathrm{~h}$ measurement period. 


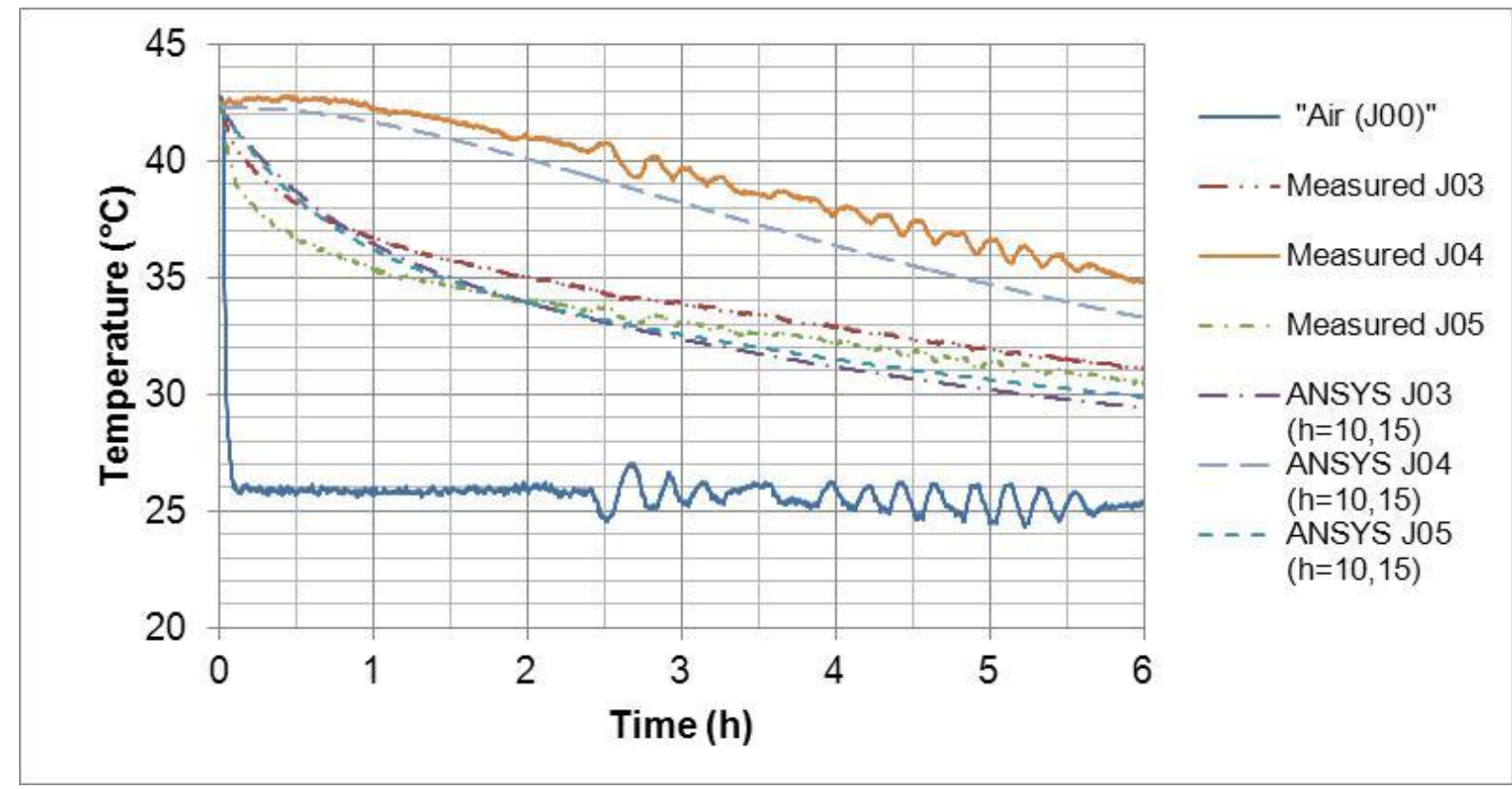

Figure 12. Measured and simulated temperatures for thermocouples J03, J04, and J05 embedded in clay block during $6 \mathrm{~h}$ of cooling after removal from oven.

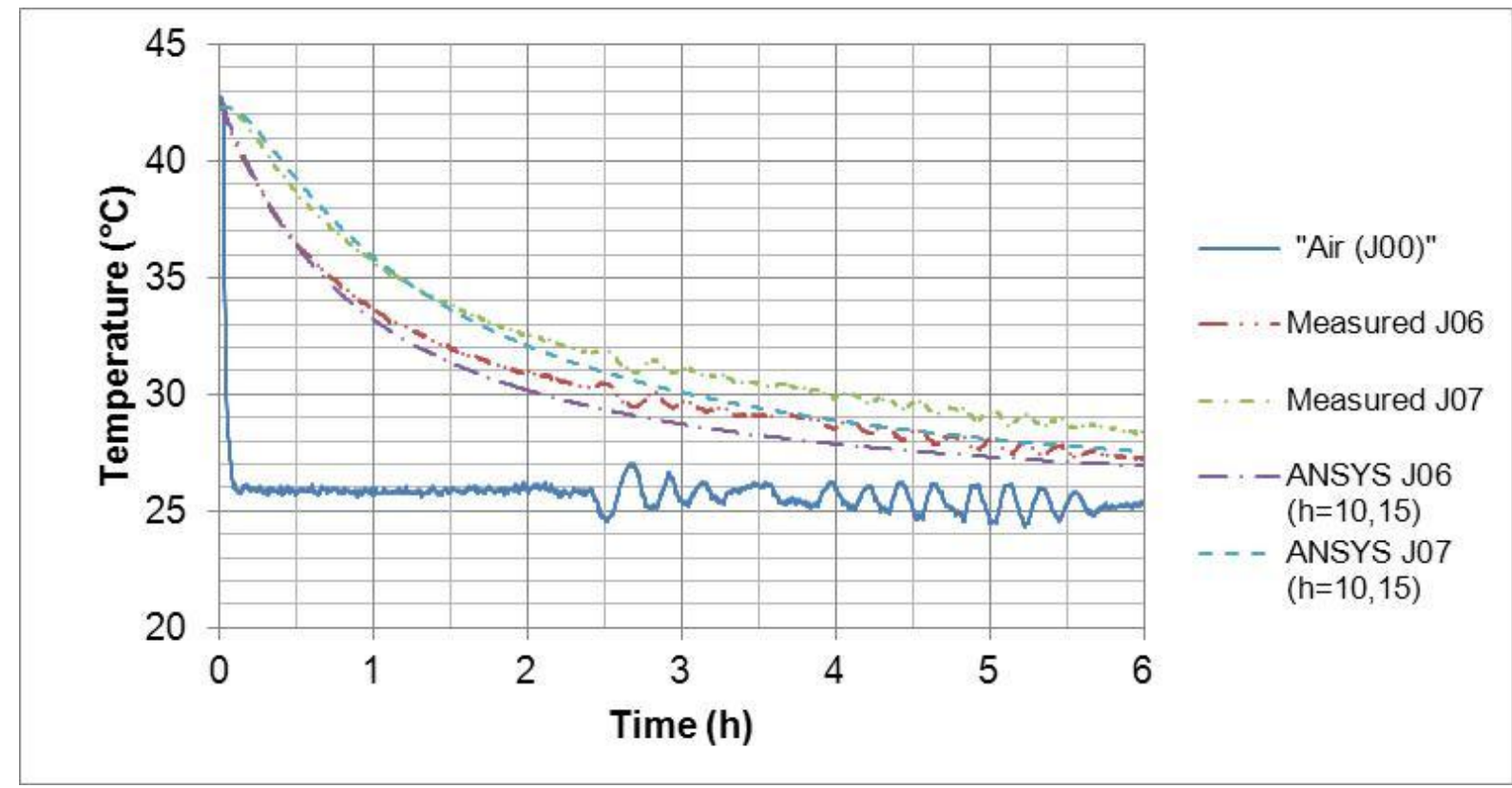

Figure 13. Measured and simulated temperatures for thermocouples $\mathrm{J06}$ and $\mathrm{J07}$ embedded in clay block during $6 \mathrm{~h}$ of cooling after removal from oven.

As a final comparison between simulation and experiment, these same thermocouple locations were monitored during the cooling and subsequent reheating of the clay block test setup. Temperatures were first monitored in the oven for about $1 \mathrm{~h}$, the block was removed from the oven once again for about $1 \mathrm{~h}$, and then returned to the oven and monitored for $16 \mathrm{~h}$ more. Experimental results for the seven thermocouples within the clay and one monitoring the air 
temperature are provided in Figure 17, while a plot of the standard deviation for the seven measurements as a function of time is provided in Figure 18. From Figures 17 and 18, it can be seen that approximately $8 \mathrm{~h}$ are required for the clay temperatures and their standard deviation to return to their baseline values after the test setup is placed back in the oven, although most of this equilibrium process is completed within $4 \mathrm{~h}$. This result is important, as it may affect test protocols for how long blocks should be equilibrated in the oven before use in testing.

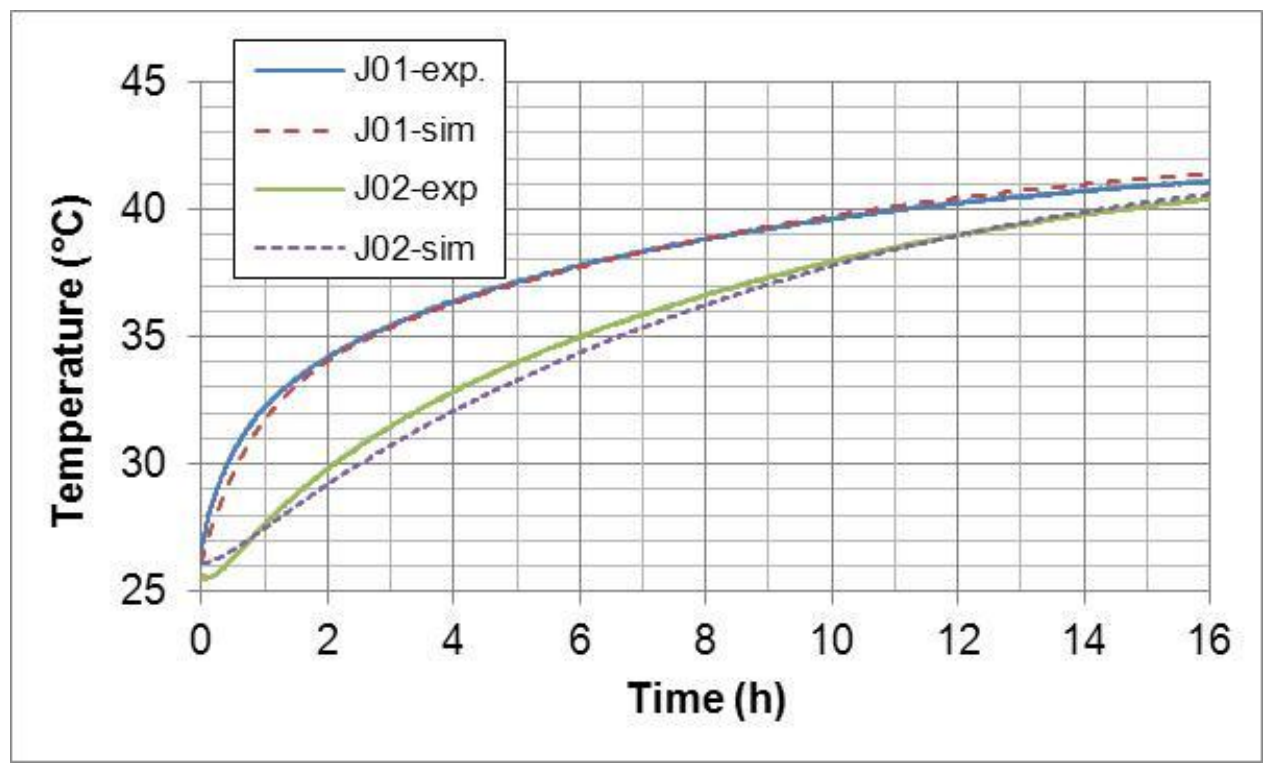

Figure 14. Measured and simulated temperatures for center of clay block (thermocouples $\mathrm{J01}$ and J02) heated for $16 \mathrm{~h}$ in the oven.

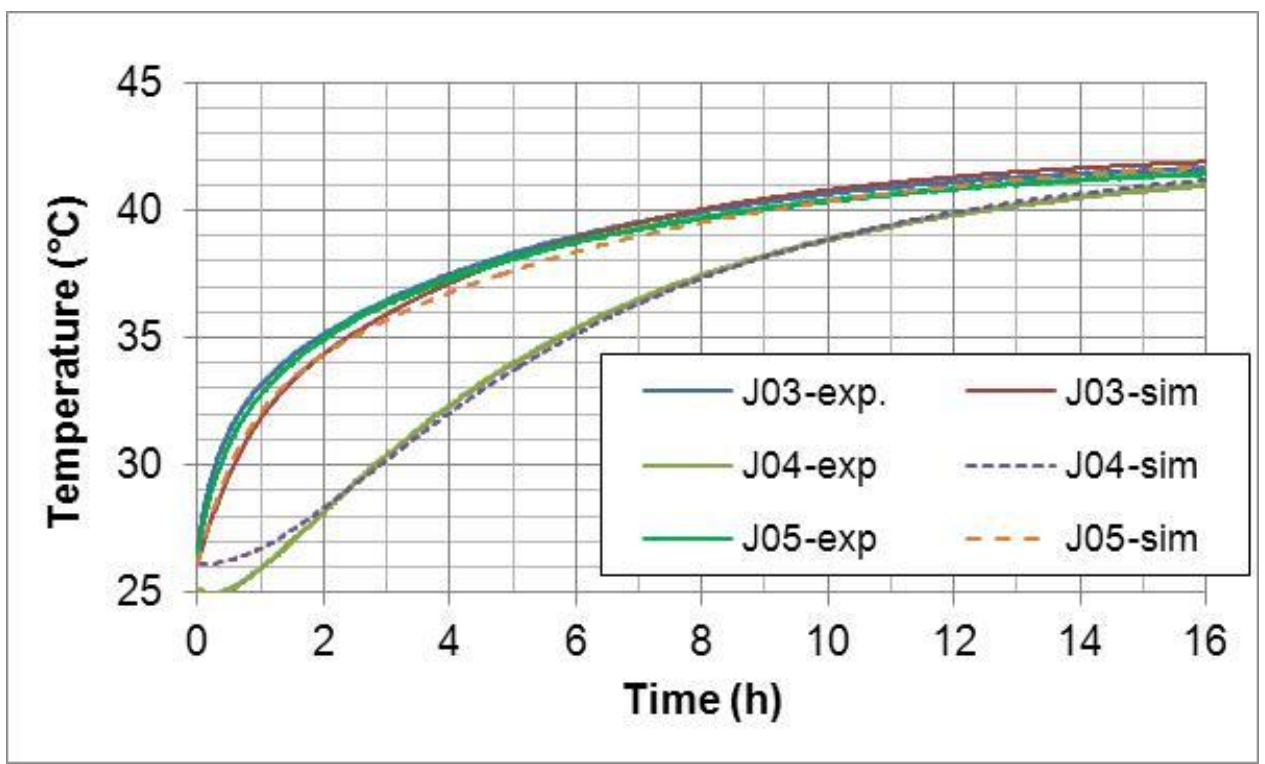

Figure 15. Measured and simulated temperatures for thermocouples J03, J04, and J05 embedded in clay block during $16 \mathrm{~h}$ of heating in the oven. 
This experiment was also simulated using the ANSYS software by first executing a $1 \mathrm{~h}$ cooling simulation and then using the final temperatures achieved throughout the test setup from that simulation as inputs for a $4 \mathrm{~h}$ (re)heating simulation. The comparison of experiment and simulation is provided in Figures 19, 20, and 21 and once again, a reasonable agreement between the experiment and the ANSYS simulation is exhibited.

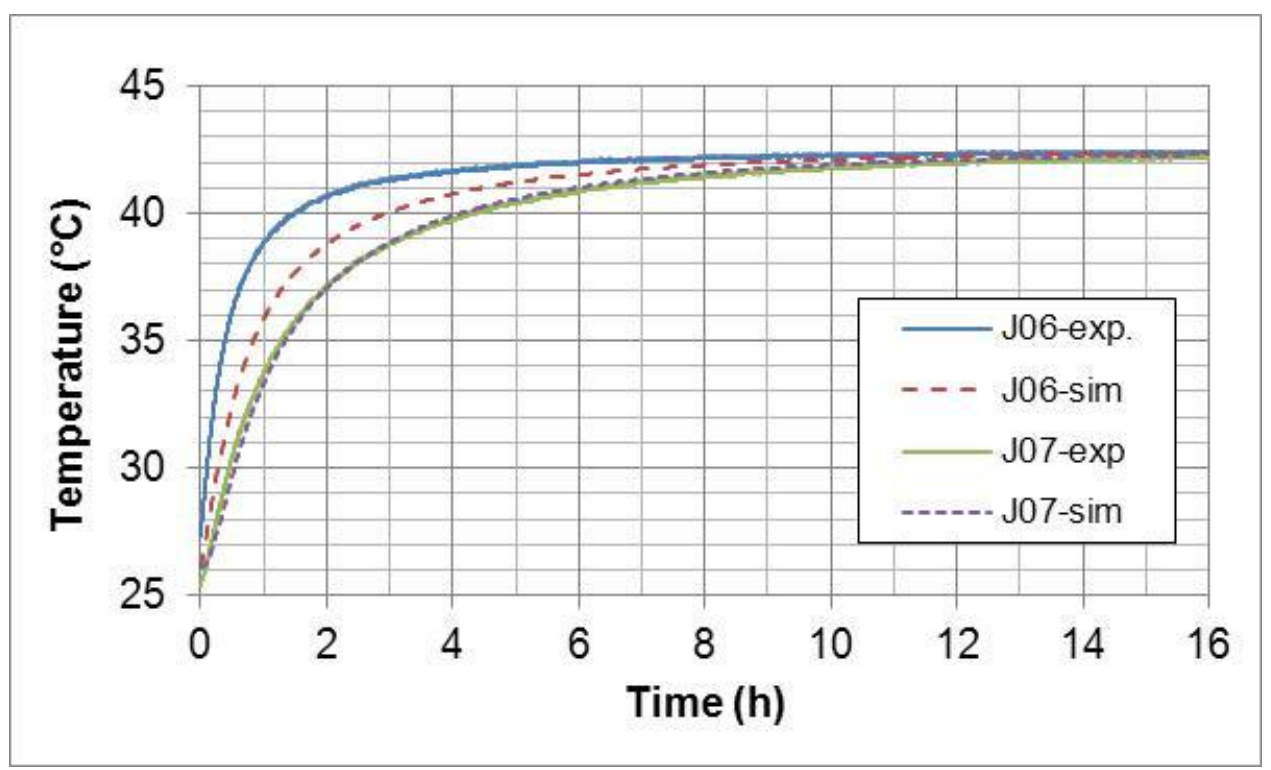

Figure 16. Measured and simulated temperatures for thermocouples $\mathrm{J06}$ and $\mathrm{J07}$ embedded in clay block during $16 \mathrm{~h}$ of heating in the oven.

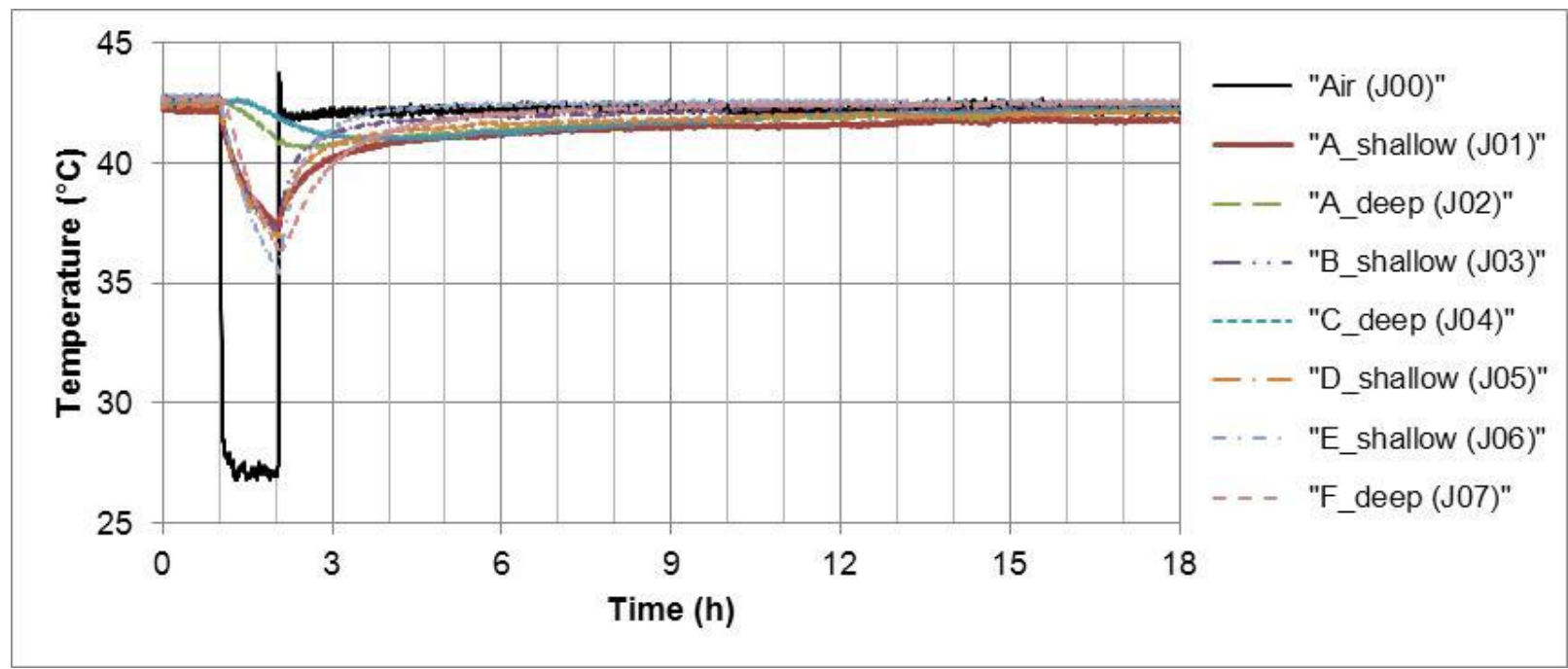

Figure 17. Measured thermocouple temperatures for the case of removing an equilibrated clay box test setup from the oven and monitoring its cooling over the course of $1 \mathrm{~h}$, followed by its reheating over the course of $16 \mathrm{~h}$. 


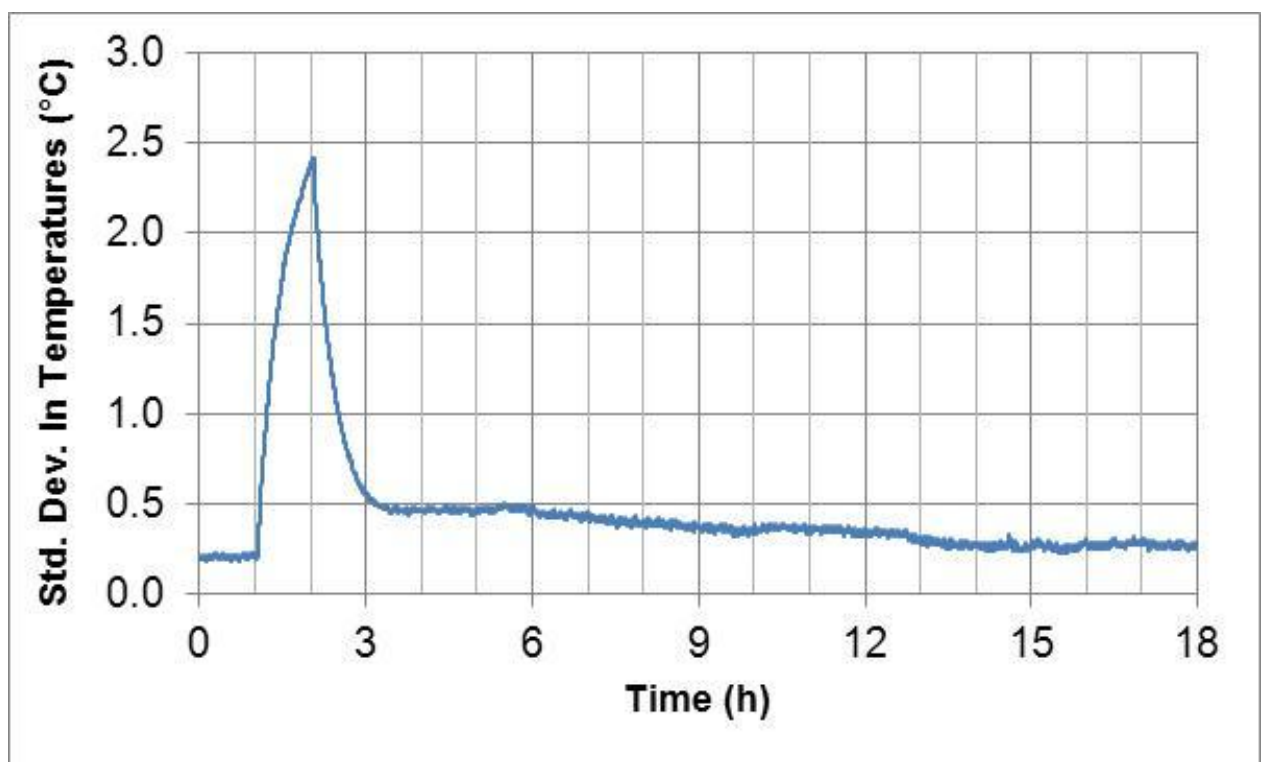

Figure 18. Standard deviation for the seven measured thermocouple temperatures as a function of time.

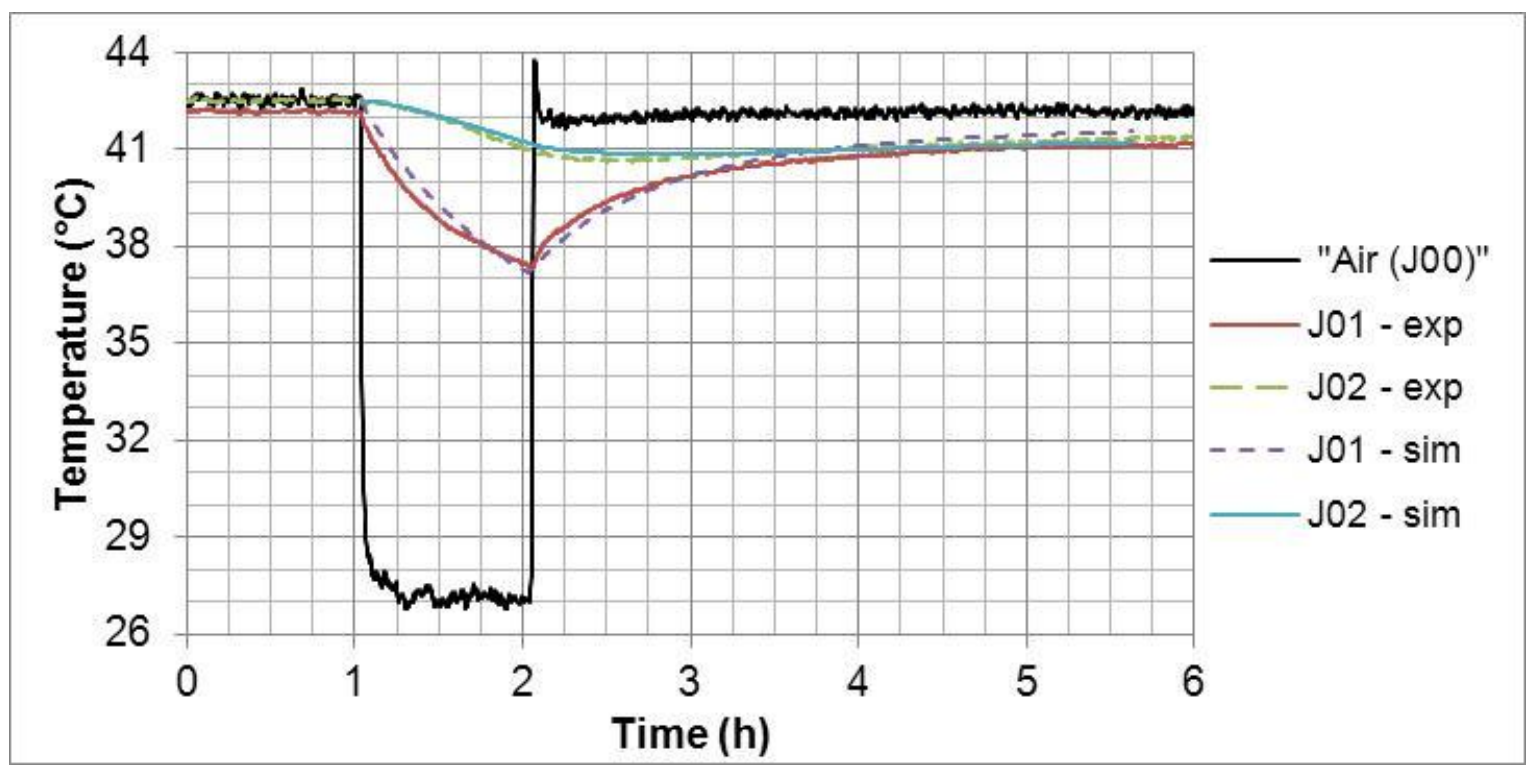

Figure 19. Measured and simulated temperatures for center of clay block (thermocouples J01 and J02) first cooled for $1 \mathrm{~h}$ and then (re)heated for $4 \mathrm{~h}$ in the oven.

Since some experimental setups use an aluminum frame, as opposed to a steel frame, surrounding the test setup, ANSYS simulations were conducted for both materials for their currently employed geometries. In the case of aluminum, a constant convection heat transfer coefficient of $10 \mathrm{~W} /\left(\mathrm{m}^{2} \cdot \mathrm{K}\right)$ was used for the clay, plywood, and aluminum exposed surfaces, since the aluminum frame is typically not U-shaped like the steel. In each case, a $6 \mathrm{~h}$ cooling simulation (using the experimental conditions of Figure 10) was conducted. Predicted temperature results are summarized in Figures 22 to 25 for the seven thermocouple locations (J01 to J07) and also for the exposed metal surface and metal-clay interface temperatures. 


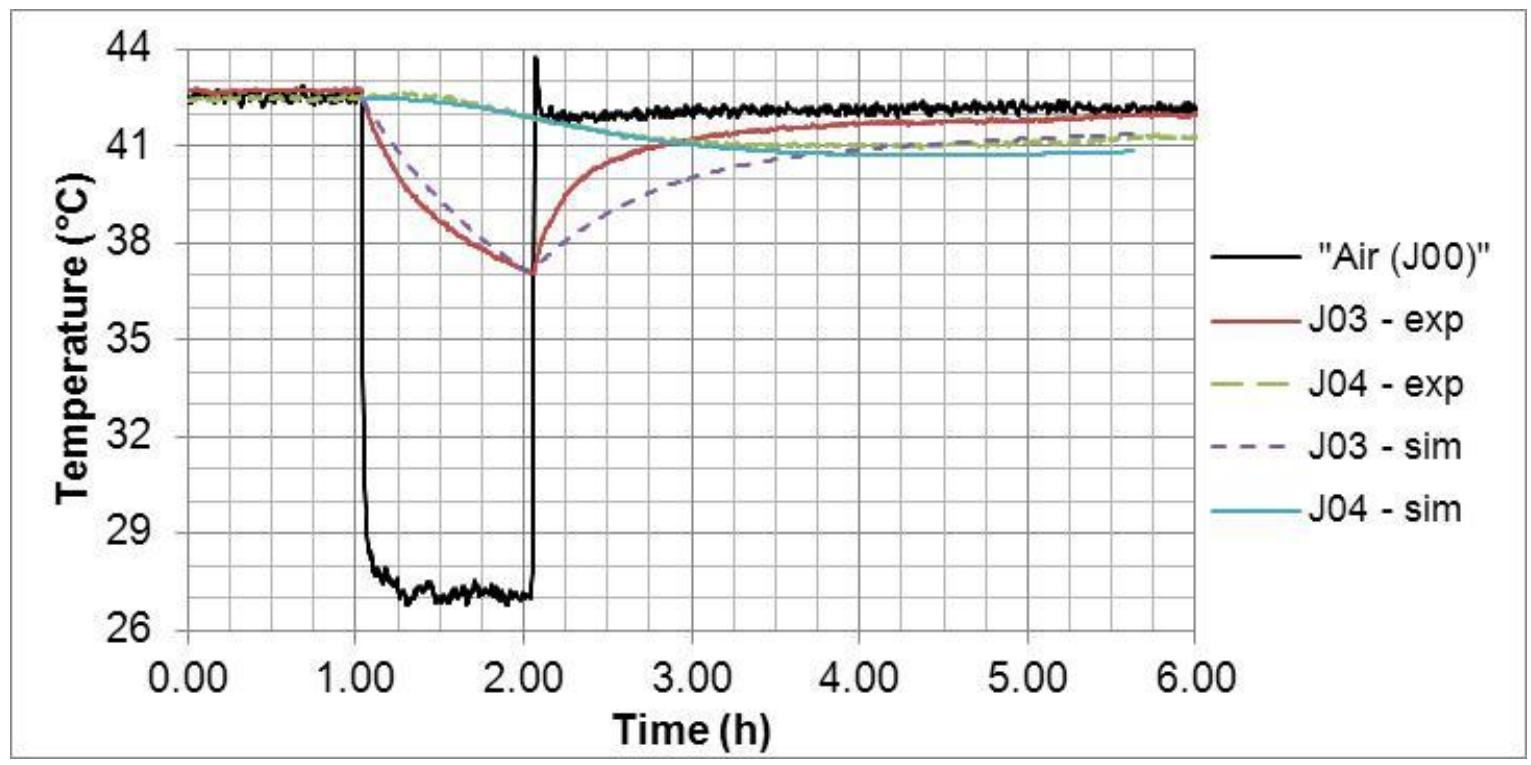

Figure 20. Measured and simulated temperatures for thermocouples J03 and J04 when clay block test setup is first cooled for $1 \mathrm{~h}$ and then (re)heated for $4 \mathrm{~h}$ in the oven.

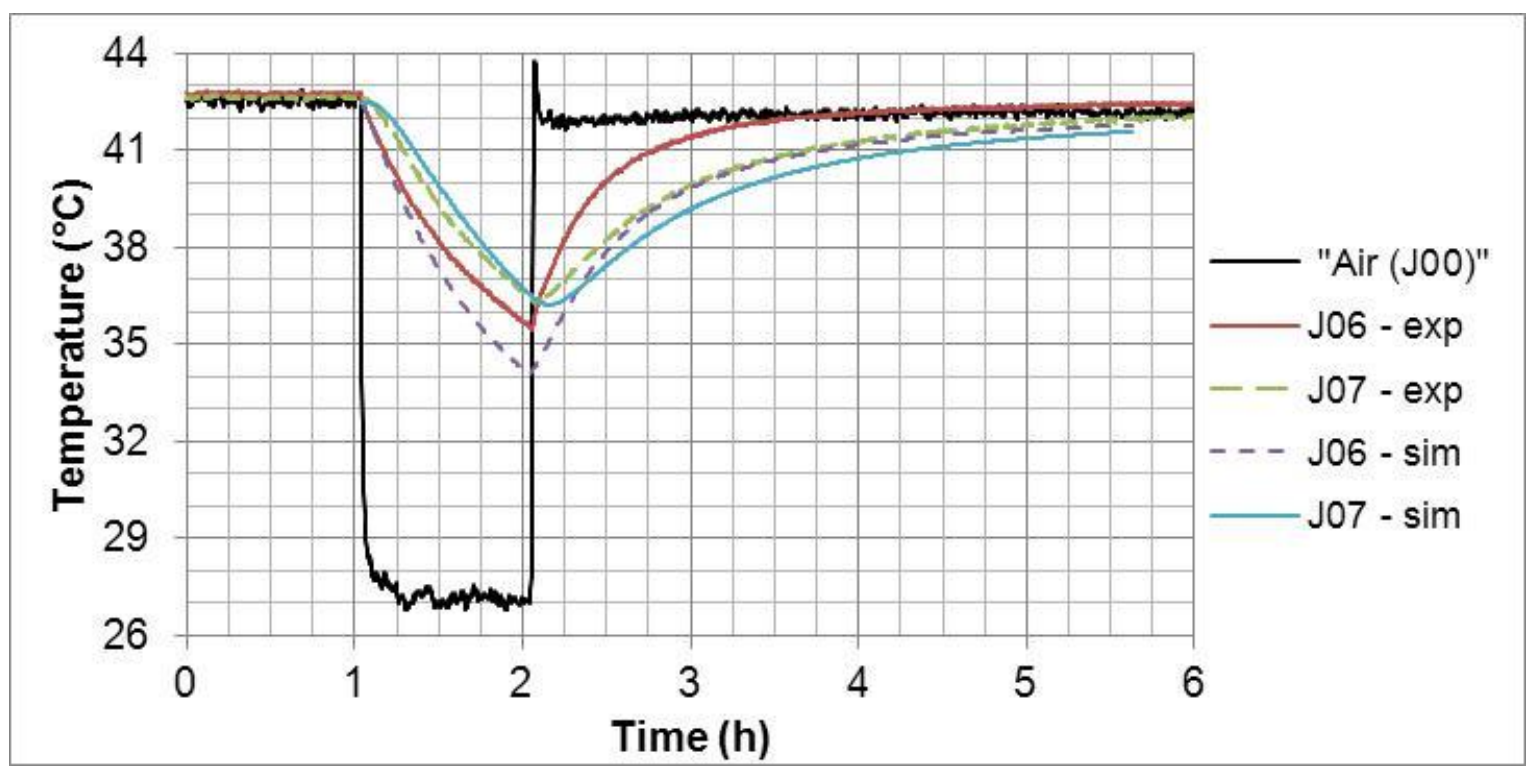

Figure 21. Measured and simulated temperatures for thermocouples J06 and J07 when clay block test setup is first cooled for $1 \mathrm{~h}$ and then (re)heated for $4 \mathrm{~h}$ in the oven.

Details on the differences in modeling geometries between the aluminum and steel frames are provided in Appendix A. The choice of the metal frame is seen to have only a very small influence on the temperature response of central region of the clay box. As one moves towards the clay-metal interfaces, the temperature deviation between aluminum and steel becomes greater. In general, the clay temperatures for the setup with the steel frame are lower than those for the setup with the aluminum frame, at least partially due to the choice to employ a convection coefficient of $15 \mathrm{~W} /\left(\mathrm{m}^{2} \cdot \mathrm{K}\right)$ for the exposed steel surfaces and only a value of $10 \mathrm{~W} /\left(\mathrm{m}^{2} \cdot \mathrm{K}\right)$ for the exposed aluminum surfaces. While aluminum is significantly less dense 


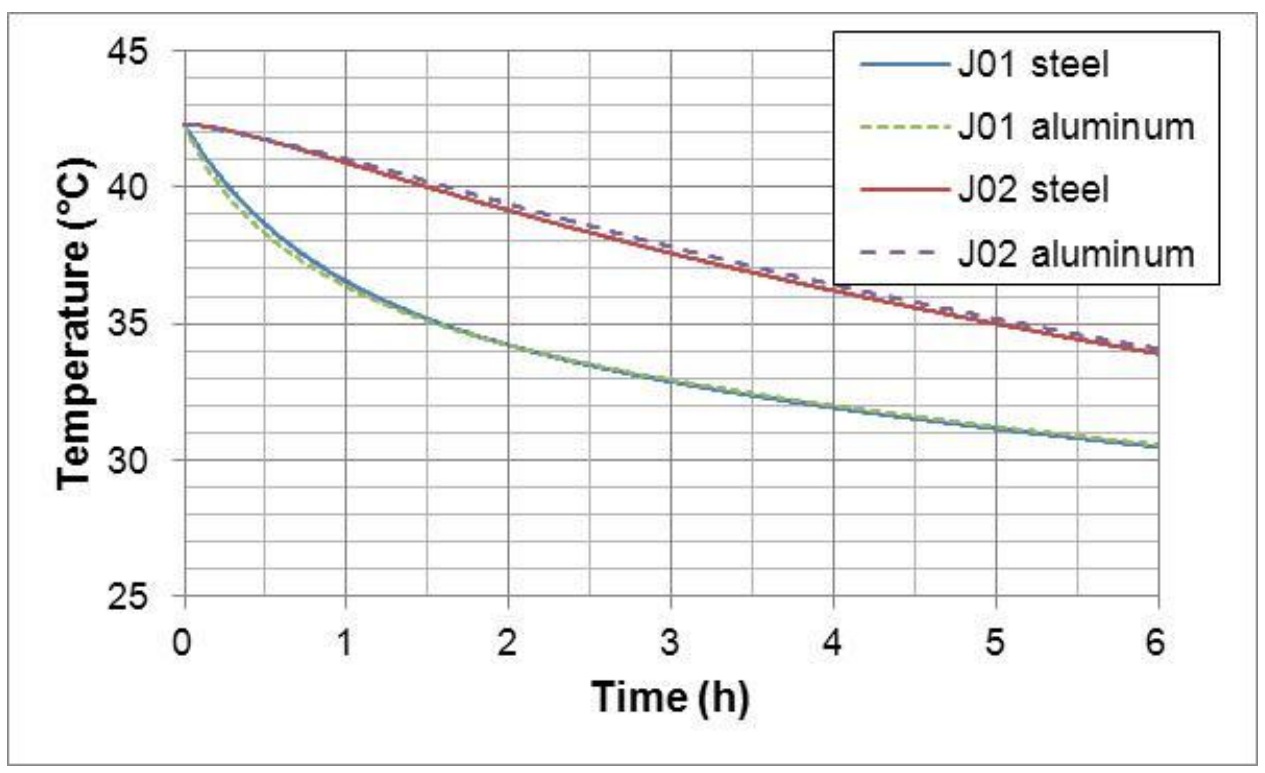

Figure 22. Comparison of predicted temperatures for thermocouples J01 and J02 for steel and aluminum frame clay block test setup geometries.

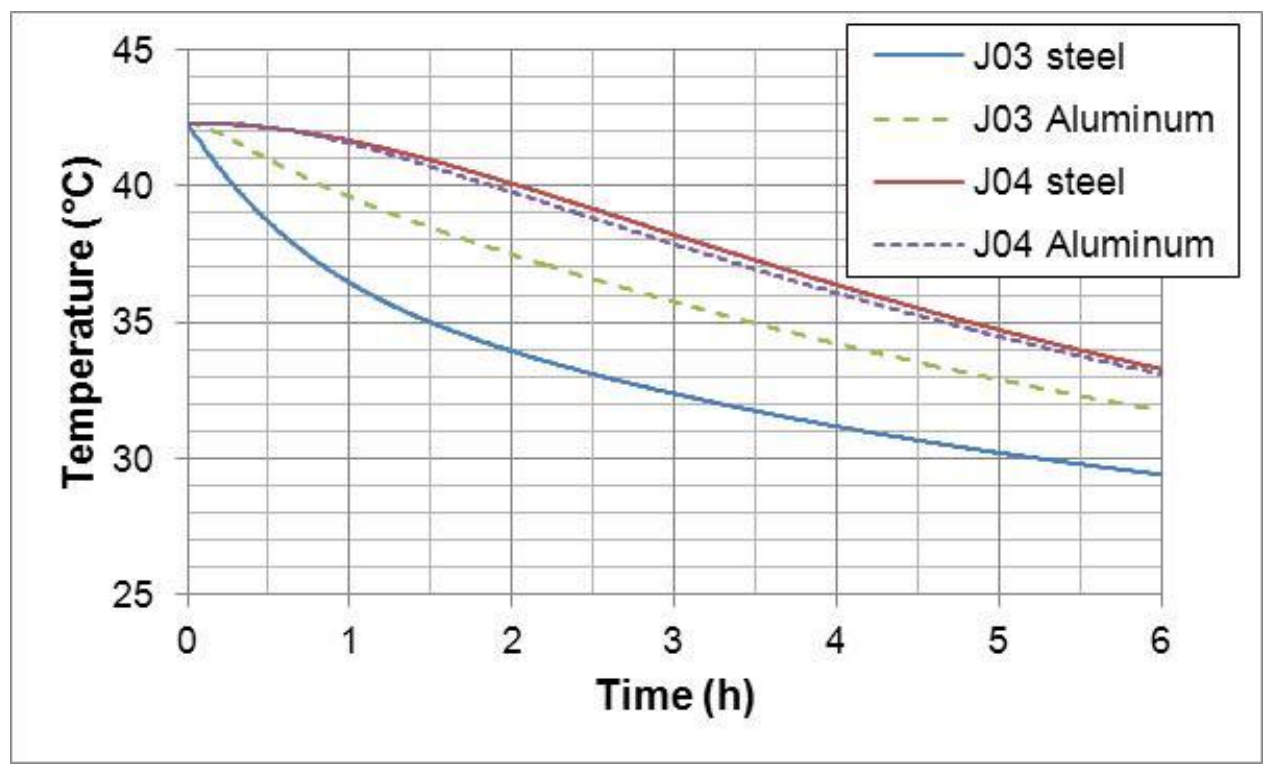

Figure 23. Comparison of predicted temperatures for thermocouples J03 and J04 for steel and aluminum frame clay block test setup geometries.

than steel, for the specific geometries described in Appendix A, the thermal mass of the aluminum frame, computed as the product of $\rho \mathrm{C}_{\mathrm{p}} \mathrm{V}$, is actually about $15 \%$ greater than that of the steel frame. While the two thermal masses are comparable, the aluminum has a thermal conductivity that is over 13 times that of the steel. With this very high thermal conductivity, as seen in Figure 25, only a very small temperature gradient can be maintained across the aluminum thickness in comparison to that which can be supported across the steel. However, due to the dominating thermal mass of the clay itself, the temperatures in the central region of the clay block (Figure 22) for these two framing systems are nearly identical during the $6 \mathrm{~h}$ of cooling. If 
equivalent experimental data were available for the cooling of an aluminum frame test setup, the hypothesis of employing a single convection coefficient for all exposed surfaces (clay, plywood, and aluminum) could be validated.

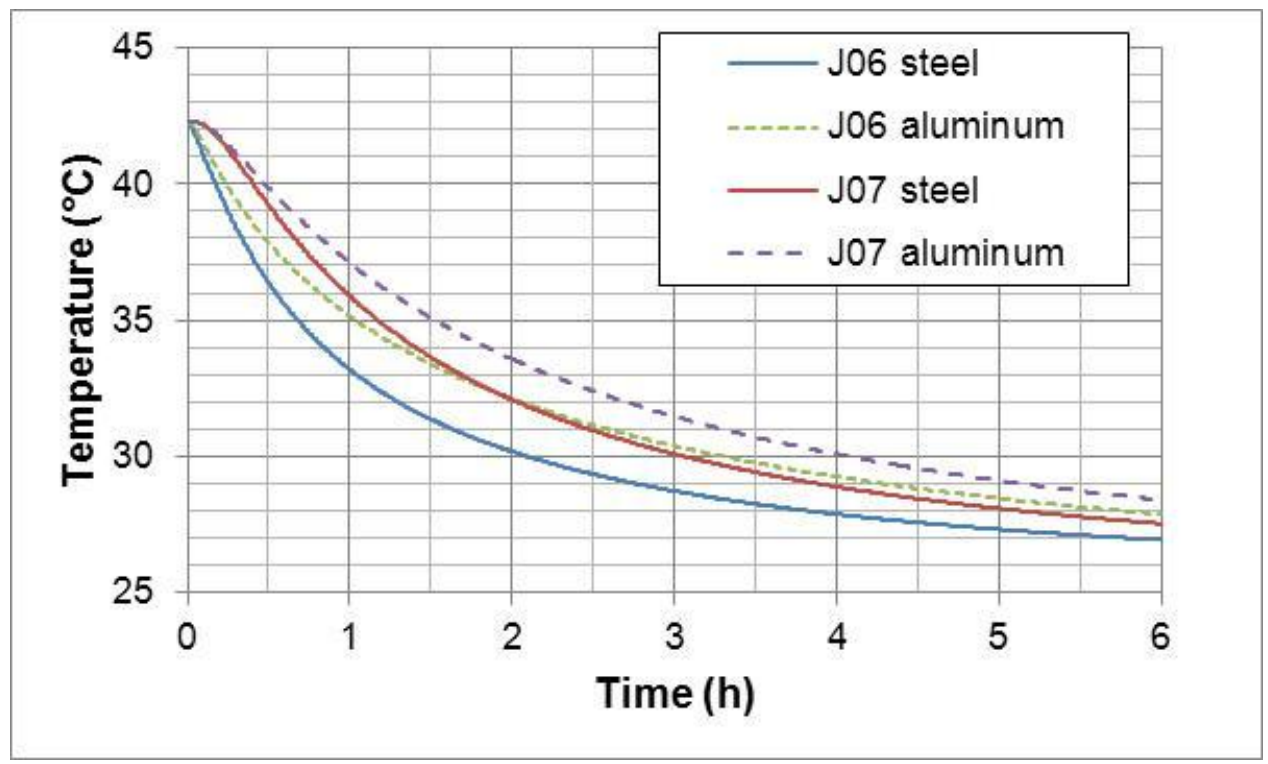

Figure 24. Comparison of predicted temperatures for thermocouples J06 and J07 for steel and aluminum frame clay block test setup geometries.

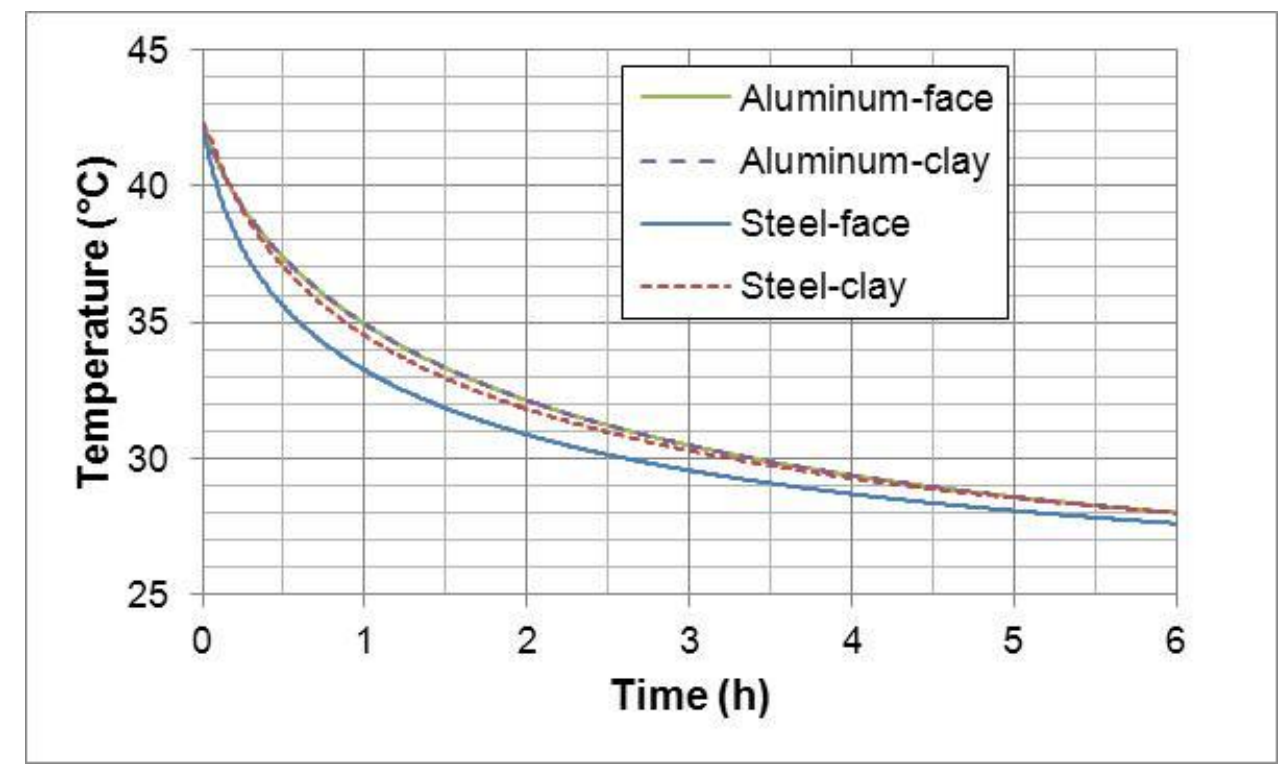

Figure 25. Predicted metal frame temperatures for the cases of aluminum and steel frames.

Another study using the ANSYS simulations concerned the possibility of separating the clay block from the steel (metal) frame using a strip of $12.7 \mathrm{~mm}(1 / 2$ ") thick polystyrene insulation (thermal properties provided in Table 3). For this comparison, the convection coefficient for the exposed steel surfaces was set at $20 \mathrm{~W} /\left(\mathrm{m}^{2} \cdot \mathrm{K}\right)$ in both cases to represent a worst case scenario. The results presented in Figures 26 to 28 for the clay block temperatures 


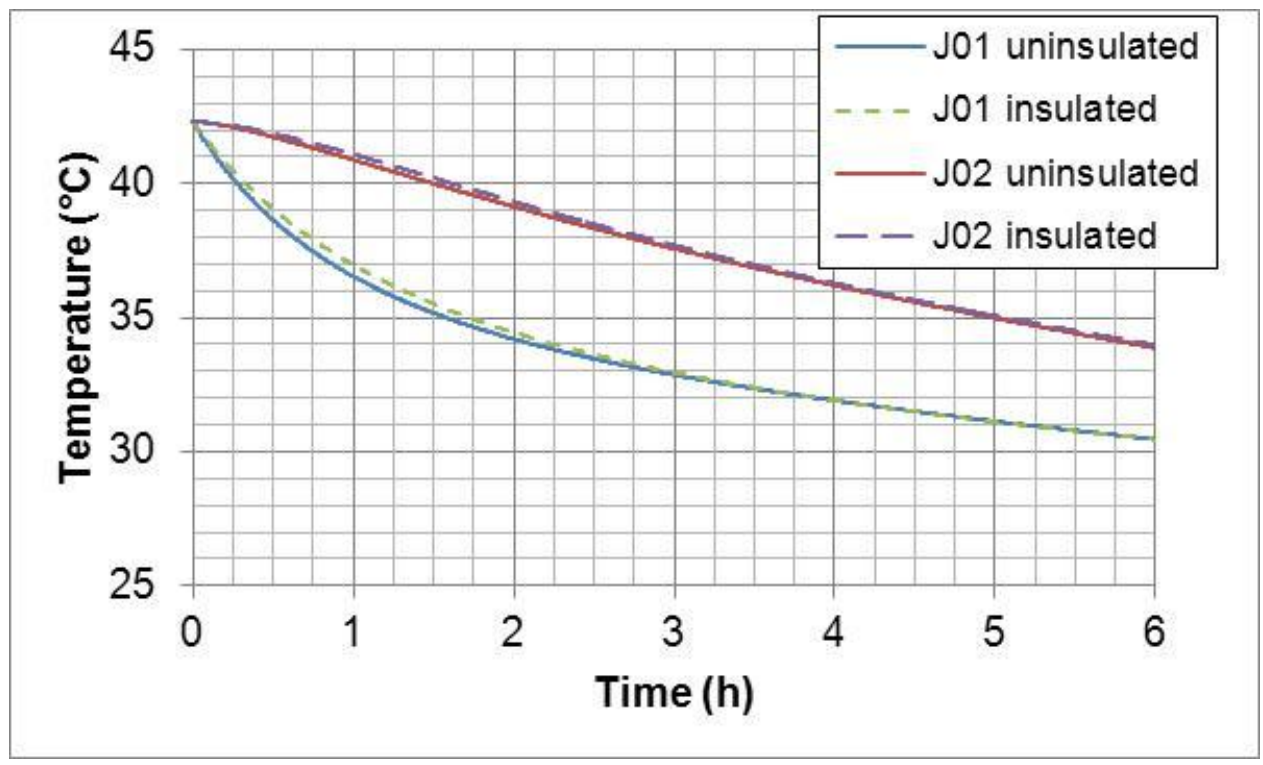

Figure 26. Comparison of clay temperatures for thermocouples J01 and J02 for uninsulated and insulated steel frames.

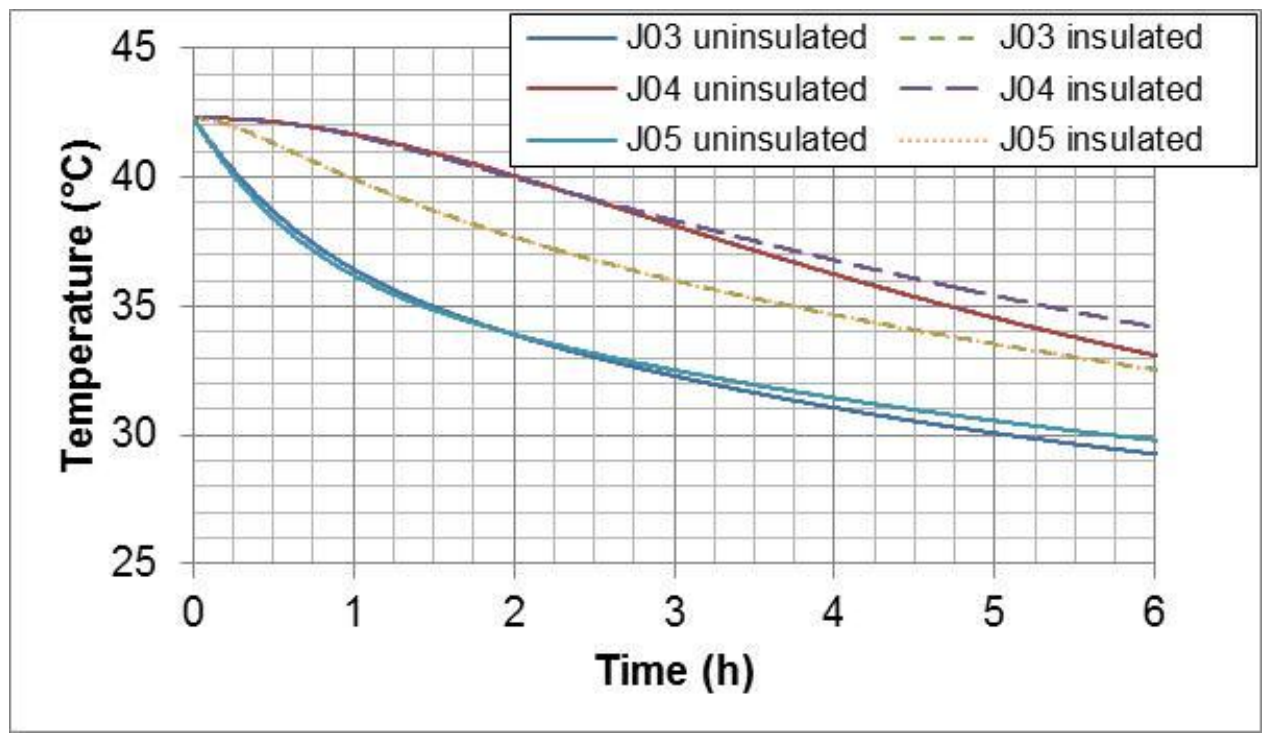

Figure 27. Comparison of clay temperatures for thermocouples J03, J04, and J05 for uninsulated and insulated steel frames.

and in Figure 29 for the steel temperatures indicate a significant improvement due to the presence of the insulation. Specifically, in Figure 28, the clay corner temperature for thermocouple $\mathrm{J} 06$ remains about $4{ }^{\circ} \mathrm{C}$ higher, $1 \mathrm{~h}$ after removal from the oven, when the insulation is present. The clay (center) face temperature exhibited a slight, but still measurable, difference in temperature after removal from the oven. As would be expected, the insulation has the greatest effect on the clay temperatures near the clay-steel or clay-insulation interface. The simulation results indicate that using the insulation, rather than significantly increasing the time after removal from the oven during which the clay box test set up can be employed for active 


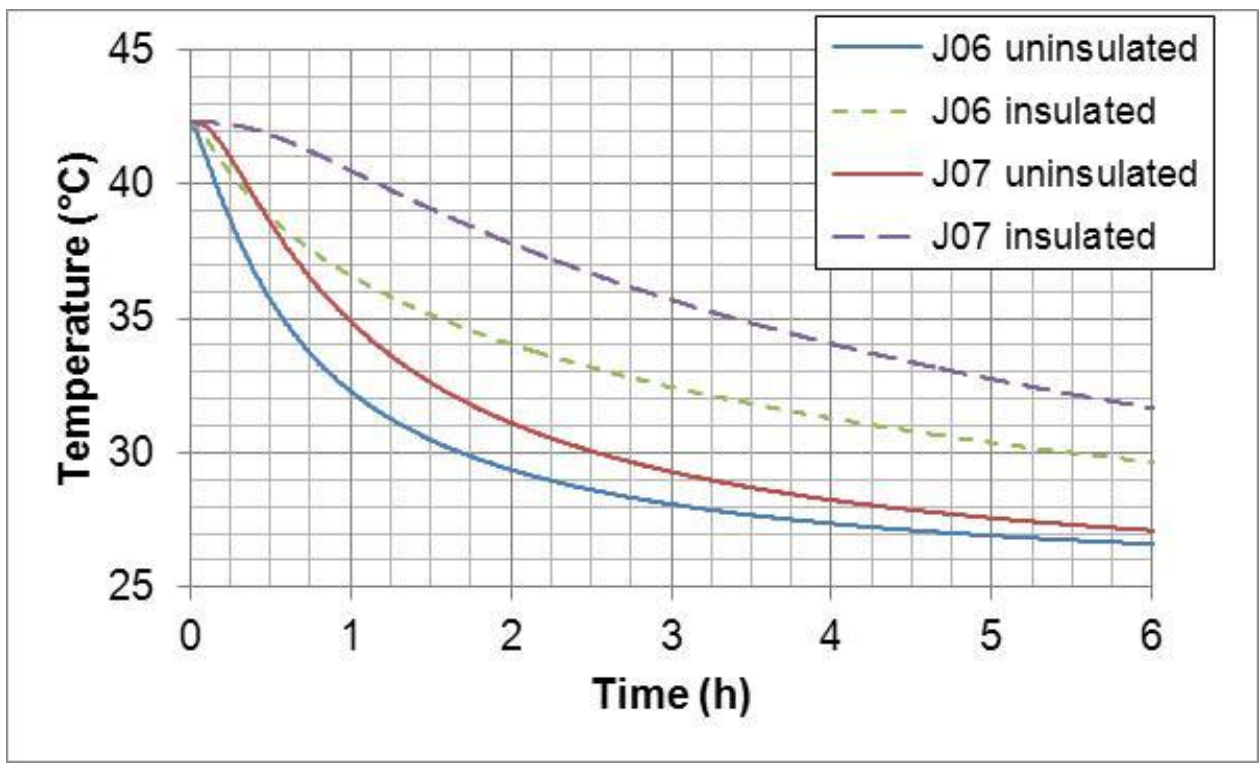

Figure 28. Comparison of clay temperatures for thermocouples $\mathrm{J06}$ and $\mathrm{J07}$ for uninsulated and insulated steel frames.

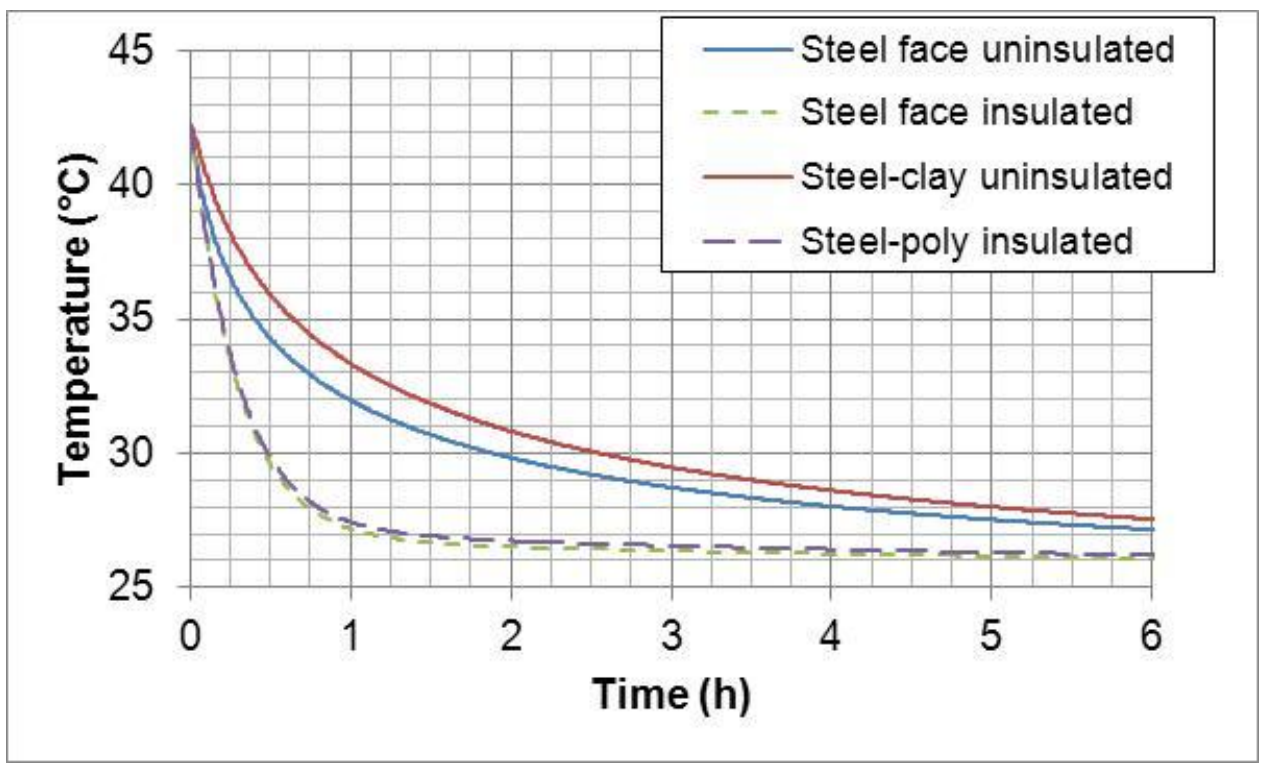

Figure 29. Comparison of steel face and interface temperatures for uninsulated and insulated steel frames.

testing, will instead provide a more uniform clay block temperature from the center to its edges. This could perhaps increase the viable testing area for firing the bullets or at least decrease the deviation in clay (thermal and mechanical) properties within the generally employed (accepted) testing area.

While these simulations investigated placing the polystyrene strip between the clay and steel, another possibility worthy of investigation would be to cover (or perhaps fill in) the exterior of the U-shaped steel frame with a polystyrene insert, perhaps after removal of the test 
setup from the conditioning oven and prior to active testing. This would likely both reduce the convection coefficient from its apparent value of $15 \mathrm{~W} /\left(\mathrm{m}^{2} \cdot \mathrm{K}\right)$ to $20 \mathrm{~W} /\left(\mathrm{m}^{2} \cdot \mathrm{K}\right)$ for the exposed steel surfaces to the nominal value of $10 \mathrm{~W} /\left(\mathrm{m}^{2} \cdot \mathrm{K}\right)$ seen for the clay and plywood, and also provide significantly reduced thermal transfer due to the extremely low thermal conductivity of the polystyrene.

A final set of simulations was conducted in ANSYS to model the thermal (cooling) response of the small cylindrical Plastilina specimens that are being employed in Hopkinson bar mechanical property testing of the ballistic clay by another research group at NIST. The question being addressed in these simulations is how quickly these much smaller specimens will cool after being removed from the oven and how to assure that they are being tested at a temperature representative of that of the clay box during actual ballistic testing. These specimens were modeled with a nominal diameter of $9.5 \mathrm{~mm}$ and a height of $4.3 \mathrm{~mm}$. Because the lab at NIST where the Hopkinson bar is located is generally rather cool, a value of $20{ }^{\circ} \mathrm{C}$ was chosen for the temperature of the environment in the simulation. For this exposure, a convection coefficient of $5 \mathrm{~W} /\left(\mathrm{m}^{2} \cdot \mathrm{K}\right)$ was employed. In addition to the ANSYS simulations, a lumped heat capacity analysis of the specimen was conducted using equation (1). Both ANSYS and the lumped heat capacity analysis results are provided in Figure 30 and Figure 31 for initial specimen temperatures of $43.3{ }^{\circ} \mathrm{C}$ and $60{ }^{\circ} \mathrm{C}$, respectively. The five reported temperatures for the ANSYS simulations correspond to the top (toptemp), bottom (bottemp), and middle (midtemp) temperatures of the clay cylinder along its central axis and the temperatures at the top (topedge) and middle (midedge) of its circular perimeter. Due to the small specimen size, along with its particular thermophysical properties, these five temperatures are quite similar and are difficult to distinguish from one another in the plots of Figure 30 and 31.

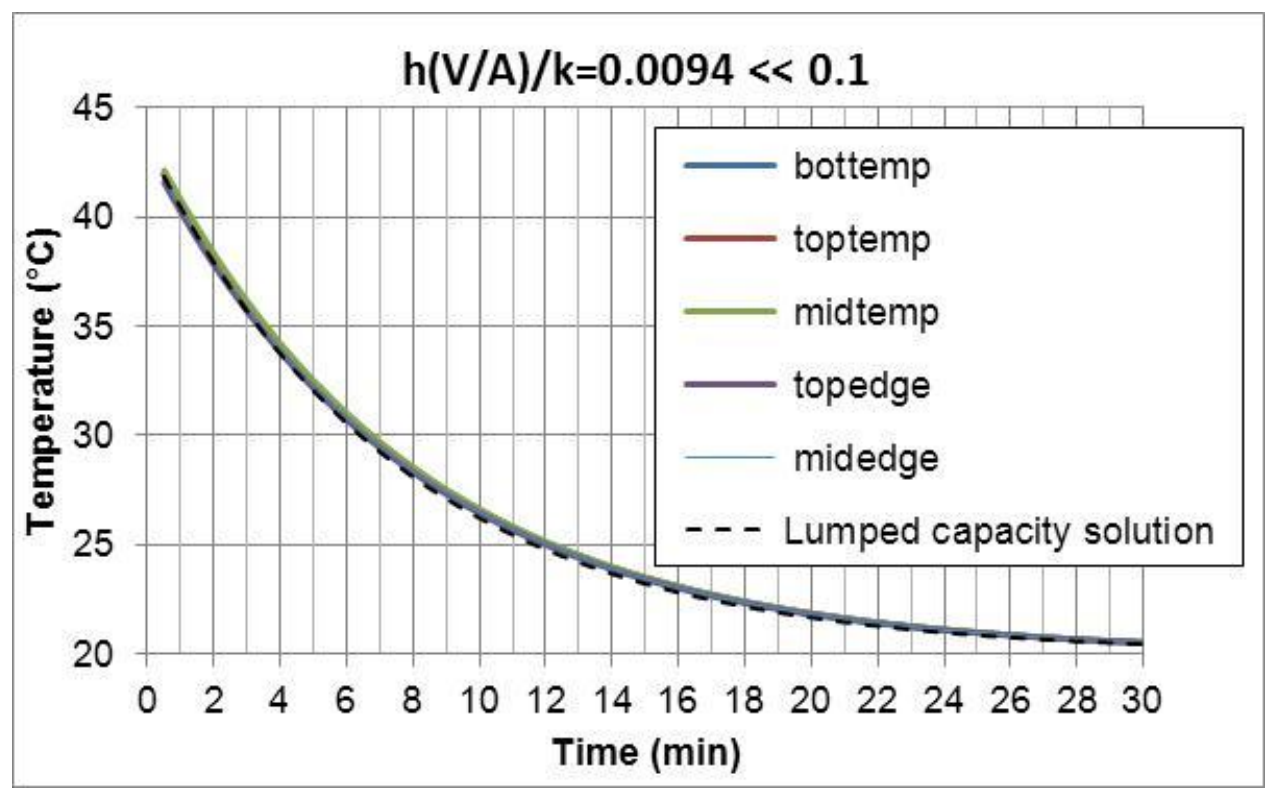

Figure 30. Predicted temperatures for small cylindrical clay specimen cooling from $43.3{ }^{\circ} \mathrm{C}$ in a laboratory at $20{ }^{\circ} \mathrm{C}$. 


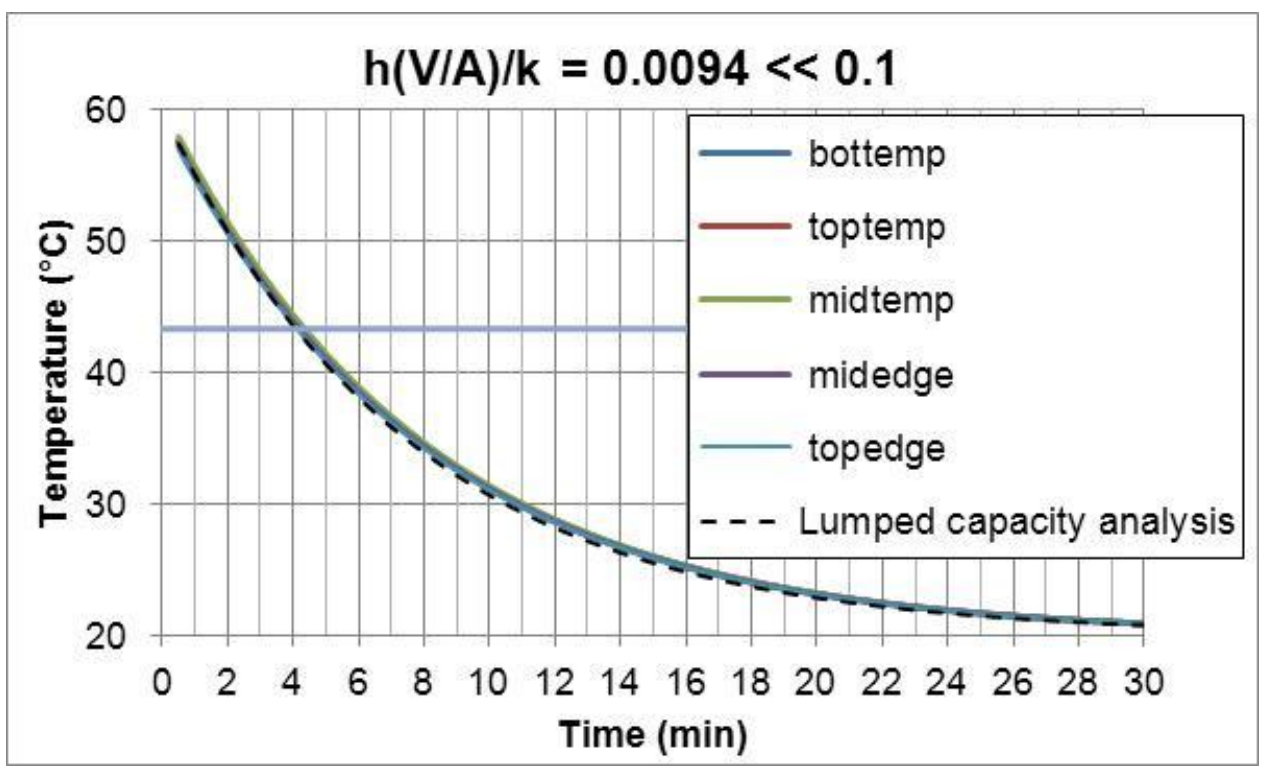

Figure 31. Predicted temperatures for small cylindrical clay specimen cooling from $60{ }^{\circ} \mathrm{C}$ in a laboratory at $20{ }^{\circ} \mathrm{C}$.

In this case, due to the much smaller size, the cooling of the clay specimen is quite rapid. Based on the simulation with the starting temperature of $60{ }^{\circ} \mathrm{C}$, if one wanted to evaluate the mechanical properties of the clay near a temperature of $43{ }^{\circ} \mathrm{C}$ (the nominal oven temperature currently used to pre-condition the ballistic clay test setup), the specimen should be assembled in the Hopkinson bar and tested at a time of about 5 minutes after being removed from the $60{ }^{\circ} \mathrm{C}$ pre-conditioning environment. The results in Figure 30 and 31 indicate that for this size (volume) specimen and these cooling conditions, the lumped heat capacity analysis provides adequate agreement with the 3-D full scale ANSYS simulations. Thus, for this application, equation (1) could be used in the place of conducting the ANSYS simulations, saving time and conserving computational resources.

\section{Conclusions and Future Research}

The current studies have demonstrated the viability of using three-dimensional finite element modeling to predict the thermal performance of the clay box test setup. By calibrating the convection coefficients against experimental temperature measurements, a generally good agreement between model and experiment was obtained. The modeling suggests that the currently employed aluminum and steel frames provide basically similar performance and that the addition of a layer of polystyrene insulation (either between the metal frame and the clay or around the exterior of the metal frame) should increase the temperature homogeneity across the complete exposed surface of the clay block within the test frame setup.

In both the simulations and the experimental studies conducted to validate them, the clay box test setup was passively exposed to a fixed environment and not subjected to impacts, etc., as would be the case in a normal testing scenario. These impacts, as well as working the clay to repair impact damage, will provide additional energy to the system, raising the clay temperature 
above the values predicted by these passive simulations. With this in mind, it is recommended that the temperature of the clay block be monitored during the course of the ballistic testing protocol as a secondary means of assuring stability of the mechanical properties of the Roma Plastilina [2]. Further improvements on the testing protocol may be obtained by developing a quantitative understanding of the mechanical properties of the clay as a function of temperature (for the temperature range of $25{ }^{\circ} \mathrm{C}$ to $50{ }^{\circ} \mathrm{C}$, for example), a topic of ongoing research within OLES at NIST.

\section{Acknowledgements}

The authors would like to thank Mr. Nathaniel Waters, OLES/NIST, for his valuable assistance throughout the project, Dr. Steven Mates, MML/NIST for valuable discussions, and Dr. William Healy, EL/NIST, for a thorough review of the manuscript. 


\section{References}

1) National Academies of Sciences, Testing of Body Armor Materials for Use by the U.S. Army - Phase II: Letter Report, National Academics Press, 2010, ISBN: 0-309-15222-4, 54 pp.

2) Esola, S., Gillich, B., Boughers, W., Meiselwitz, S., Final Report: Clay Calibration: Radial Dependence of Calibration Drop Depths, United States Army Aberdeen Test Center, July 2010.

3) Ballistic Resistance of Body Armor, NIJ Standard-0101.06, National Institute of Justice, July 2008.

4) ANSYS Mechanical APDL Thermal Analysis Guide, Release 13.0, SAS IP Inc., November 2010.

5) Holman, J.P. Heat Transfer, $5^{\text {th }}$ edition, McGraw-Hill Book Co., New York, 1981.

6) Gustafsson, S.E., "Transient Plane Source Techniques for Thermal Conductivity and Thermal Diffusivity Measurements of Solid Materials," Review of Scientific Instruments, 62 (3), 797-804, 1991.

7) Log, T., and Gustafsson, S.E., "Transient Plane Source (TPS) Technique for Measuring Thermal Transport Properties of Building Materials," Fire and Materials, 19, 43-49, 1995.

8) Bentz, D.P., "Combination of Transient Plane Source and Slug Calorimeter Measurements to Estimate the Thermal Properties of Fire Resistive Materials," ASTM Journal of Testing and Evaluation, 35 (3), 240-244, 2007.

9) Do, C.T., Bentz, D.P., and Stutzman, P.E., "Microstructure and Thermal Conductivity of Hydrated Calcium Silicate Board Materials," Journal of Building Physics, 31 (1), 55-67, 2007.

10) Bentz, D.P., "Transient Plane Source Measurements of the Thermal Properties of Hydrating Cement Pastes," Materials and Structures, 40 (10), 1073-1080, 2007.

11) Bentz, D.P., Peltz, M.A., Duran-Herrera, A., Valdez, P., and Juarez, C.A., "Thermal Properties of High-Volume Fly Ash Mortars and Concretes," Journal of Building Physics, 34 (3), 263-275, 2011.

12) Nelson, K.E., Luedke, E.E., and Bevans, J.T., "A Device for the Rapid Measurement of Total Emittance," Journal of Spacecraft and Rockets, 3 (5), 758-760, 1966.

13) ASTM E408-71(2008), "Standard Test Methods for Total Normal Emittance of Surfaces Using Inspection-Meter Techniques," ASTM Annual Book of Standards, ASTM International, West Conshohocken, 2008.

14) Heisler, M.P., "Temperature Charts for Induction and Constant Temperature Heating," Transactions of the American Society of Mechanical Engineers, 69, 227-236, 1947.

15) Lawrence Berkeley National Laboratory, Buildings.HeatTransfer.Data, http://gaia.lbl.gov/bie/modelica/releases/0.8.0/help/Buildings_HeatTransfer_Data.html, accessed March 2011.

16) The Engineering Toolbox, http://www.engineeringtoolbox.com, accessed March 2011.

17) Bentz, D.P., and Prasad, K.R., "Thermal Performance of Fire Resistive Materials I. Characterization with Respect to Thermal Performance Models," NISTIR 7401, U.S. Department of Commerce, 2007.

18) Rodriguez, F., Principles of Polymer Systems, $2^{\text {nd }}$ edition, McGraw-Hill Book Co., New York, 1982. 


\section{Appendix A - ANSYS Simulation Instructions}

ANSYS is available at NIST via several different site licenses. Here, instructions are provided for an ANSYS simulation that models cooling of the Plastilina block with plywood backing and a metal frame, employing a $1 / 4$ (volume) model to take advantage of symmetry.

This simulation using ANSYS consisted of creating a 3-D model for the cooling of the clay block with a plywood backing and a metal (steel or aluminum) frame, modeling only $1 / 4$ of the volume to take advantage of symmetry and employing the default ANSYS adiabatic boundaries as needed. The dimensions of block of clay (Plastilina \#1) are assumed as $60.96 \mathrm{~cm} \times 60.96 \mathrm{~cm} \times 13.97 \mathrm{~cm}(24$ " x 24" x 5.5"), while the plywood is $1.9 \mathrm{~cm}(3 / 4 ")$ thick. The aluminum frame is $1.27 \mathrm{~cm}(1 / 2$ ") thick. The actual steel frame pieces are U-shaped, but an equivalent thickness (to match the overall thermal mass of the steel including the handles) would be $0.65 \mathrm{~cm}(0.256$ "). Thermal properties were determined for the Plastilina and the plywood using the Hot Disk Thermal Constants Analyzer for thermal conductivity and heat capacity and either a graduated volumetric flask (commonly employed to determine the density of powders) or physical measurements of mass and dimensions for density as described earlier in this report. Thermal properties of stainless steel and aluminum were taken from the literature. The values employed in this execution of ANSYS are shown in Table 3. Based on calibration against experimentally-measured temperatures, a heat transfer coefficient of $5 \mathrm{~W} /\left(\mathrm{m}^{2} \cdot \mathrm{K}\right)$ was assumed initially for the convection coefficient at all exposed surfaces. The initial block temperature was assumed to be $42.3{ }^{\circ} \mathrm{C}$ while that of the room (surroundings) was $25.6{ }^{\circ} \mathrm{C}$.

Once execution of ANSYS was initiated on the desktop PC (workstation), the following steps were implemented (all dimensions in the ANSYS simulation were input in units of meters):

1) Change jobname (PlastilinaAl for aluminum, PlastilinaSteel for steel)

File > Change jobname

Input new jobname and click OK

2) Change title (3-D Plastilina block-plywood backing-metal frame - 1/4 model)

File > Change title

Input new title and click OK

3) Set units (mks)

This is easiest to do via a direct input on the ANSYS command line at the top of the main window by typing: /UNITS,mks

4) Define element types for analysis (Main menu is accessible from left side of ANSYS window) Main > Preprocessor > Element Type > Add/Edit/Delete

A thermal mass, solid, Brick 8-node 70 (also known as Solid70 within ANSYS) element is selected 
5) Define material properties (with values from Table 3)

Main > Preprocessor > Material Props > Material Models

Select Thermal and input Conductivity (Isotropic), Heat Capacity, Density for material 1

Create new material and input conductivity, heat capacity, and density for material 2

Create new material and input conductivity, heat capacity, and density for material 3 (Al or Steel)

Exit

6) Create the block of clay, the plywood backing, and two metal bars in the $1 / 4$ model

Main > Preprocessor > Modeling > Create > Volume > Block > By Dimensions

Enter the dimensions of the block by entering starting and ending coordinates for $\mathrm{X}, \mathrm{Y}$, and $\mathrm{Z}$ directions $(0,0.3048),(0,0.3048),(0,0.1397)$ for the clay, $(0,0.3048),(0,0.3048)$, $(0.1397,0.1587)$ for the plywood, $(0,0.3048),(0.3048,0.3175),(0,0.1397)$ for one $\mathrm{Al}$ bar and $(0.3048,0.3175),(0,0.3048),(0,0.1397)$ for the $2^{\text {nd }} \mathrm{Al}$ bar; for steel, these values are $(0,0.3048)$, $(0.3048,0.3113),(0,0.1397)$ and $(0.3048,0.3113),(0,0.3048),(0,0.1397)$, respectively

7) Select the materials for the volumes

Main > Preprocessor $>$ Meshing $>$ Mesh Attributes $>$ Picked Volumes

Use the selection tool to pick first volume 1 (clay), then volume 2 (plywood) and then volumes (3) and (4) and assign them the appropriate material ID (1,2, and 3 respectively)

8) Mesh the model

Main > Preprocessor $>$ Meshing > Mesh Tool

Use a smart size of 6 for spatial resolution, then press Mesh and Pick All for volumes

9) Use the Contact wizard to connect the material pairs (clay/plywood and clay/metal) over their common areas

Main > Preprocessor $>$ Modeling $>$ Create $>$ Contact Pair

First select the target surface area (\#2)

Select the contact surface area (\#7)

Turn on create symmetric pair

Set contact conductance to a high value to minimize contact resistance (e.g., 10)

Create

Repeat for the two metal bars for areas \#4-\#15 and \#6-\#23 with a contact conductance of 100 for steel and 500 for aluminum

10) Set analysis type for preprocessor

Main > Preprocessor $>$ Loads $>$ Analysis Type $>$ New Analysis

Select Transient analysis

Select Full analysis 
11) Define initial conditions and boundary conditions for convection

Main > Solution > Define Loads > Apply > Thermal > Convection > On Areas

Select areas $(1,8,10,12,13,14,16,18,19,20,22,24)$ and set the film or convection

coefficient and ambient temperature for the problem $\left(10 \mathrm{~W} /\left(\mathrm{m}^{2} \cdot \mathrm{K}\right)\right.$ and $\left.25.6{ }^{\circ} \mathrm{C}\right)$ In this symmetry-based setup, areas $3,5,9,11,17$ and 21 will be adiabatic surfaces (default in ANSYS). For steel, areas $(1,8,10,12)$ are assigned a convection coefficient of $10 \mathrm{~W} /\left(\mathrm{m}^{2} \cdot \mathrm{K}\right)$ while areas $(12,13,14,16,18,19,20,22,24)$ are assigned a convection coefficient of $20 \mathrm{~W} /\left(\mathrm{m}^{2} \cdot \mathrm{K}\right)$.

12) Define initial temperature of clay block and plywood backing

Main > Solution > Define Loads > Apply > Initial Conditions > Define

Pick all nodes, set DOF to TEMP, and set temperature to $42.3{ }^{\circ} \mathrm{C}$

13) Set analysis type for solution

Main > Solution > Analysis Type > New Analysis

Select Transient Analysis

14) Set run time options

Main > Solution > Load Step Opts > Time/Frequency > Time - Time Steps

Set Maximum duration and time step (so that 1000 output points are generated)

Run for only $6 \mathrm{~h}$ with a $30 \mathrm{~s}$ step size $(6 \times 3600=21600 \mathrm{sec})$

Select stepped as opposed to ramped

Main > Solution > Load Step Opts > Output Ctrls > DB/Results File

Select every substep to store output

15) At this point and perhaps earlier, use the SAVE_DB button to save your work

16) Solve the problem

Main > Solution > Solve > Current LS

17) Define points of interest from the Parameters, Scalar Parameters menu sequence

$\mathrm{J} 01 \_\mathrm{pt}=\operatorname{node}(0,0,0.016)$

$\mathrm{J} 02 \_\mathrm{pt}=$ node $(0,0,0.07)$

J03_pt=node $(0.1524,0.1524,0.013)$

J04_pt=node $(0.1524,0.1524,0.07)$

J05_pt=node $(0,0.1524,0.013)$

J06_pt=node $(0.2794,0.2794,0.013)$

J07_pt=node $(0.2794,0.2794,0.07)$

Metal_face_pt $=$ node $(0,0.3175,0.07)$ or node $(0,0.3113,0.07)$ for steel

Metal_clay_pt=node $(0,0.3048,0.07)$

18) Select the points to be plotted

Main > Timehist Postpro

Use + to add variables (center, face, corner for example)

Select these to be nodal temperatures from the Nodal solution, DOF solution 
It is also from this window that individual temperatures (lists) can be output to files for importing into Excel, etc.

Main > TimeHist Postpro > Graph Variables

This will graph the selected variables. This image can be captured (to a jpeg format file, for example) via the printer button at the top of the ANSYS window.

19) To create an animation (avi) file

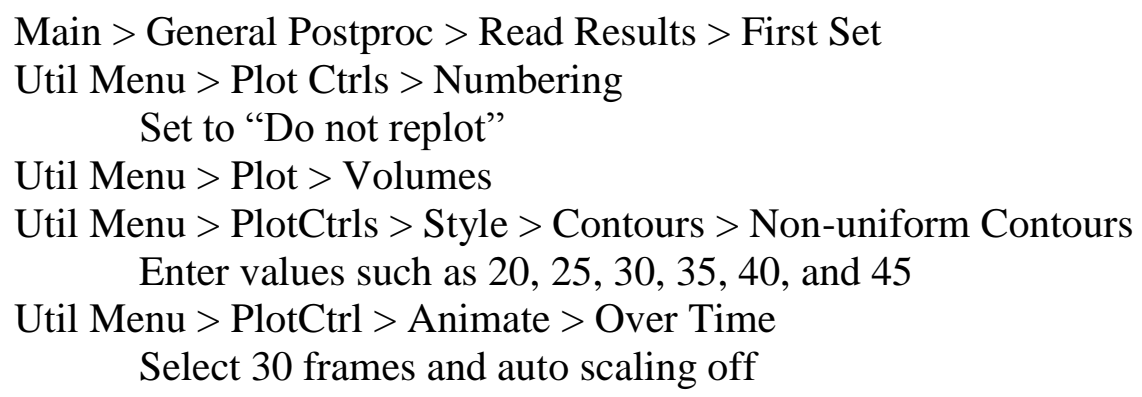

Estimated run times on a typical desktop (vintage 2004) Windows XP PC --- about $5 \mathrm{~h}$ for $\mathrm{Al}$ frame and $8 \mathrm{~h}$ for steel frame 